\title{
Conventional Breeding, Molecular Breeding and Speed Breeding; Brave Approaches to Revamp the Production of Cereal Crops
}

\author{
Muhammad Haroon ${ }^{1 \dagger}$, Muhammad Mubashar Zafar ${ }^{2 \dagger}$, Muhammad Awais Farooq ${ }^{3}$, \\ Rabail Afzal', Maria Batool ${ }^{4}$, Fahad Idrees ${ }^{1}$, Usman Babar ${ }^{5}$, Abdul Saboor Khan ${ }^{6}$, \\ Huijuan Mo ${ }^{2}$ Lin $\mathrm{Li}^{1 *}$, Maozhi Ren ${ }^{2 *}$,
}

1: National Key Laboratory of Crop Genetic Improvement, Huazhong Agricultural University, Wuhan, China

${ }^{2}$ State Key Laboratory of Cotton Biology; Key Laboratory of Biological and Genetic Breeding of Cotton, The Ministry of Agriculture; Institute of Cotton Research, Chinese Academy of Agricultural Science, Anyang, 455000, Henan, China.

${ }^{3}$ Department of Plant Breeding and Genetics, University of Agriculture Faisalabad, Faisalabad, Pakistan

4: College of Plant Science and Technology, Huazhong Agricultural University, Wuhan, China

5: School of Agricultural Sciences, Zhengzhou University, Zhengzhou, Henan, China.

6: Graduate School of Chinese Academy of Agricultural Sciences, Beijing, China

Corresponding author: $\mathrm{Lin} \mathrm{Li}$

hzaulilin@mail.hzau.edu.cn

Corresponding author: Maozhi Ren

renmaozhi01@,caas.cn 


\begin{abstract}
:
Conventional plant breeding methods exploit already existing genomic variation in plants to develop a variety in 8 to 10 years, which can decrease the genetic variability of plant's genome. The ever-increasing food demand of cereals crops cannot be met by the traditional breeding methods. In order to increase the food production in less time, there is a dire need to improve the breeding methods. Several conventional and molecular breeding methods are being used to improve the crops traits. Molecular researchers have developed new genome editing tools like CRISPR/Cas9, CRISPR/Cpf1, prime editing, base editing, dcas9 epigenetic modification, and several other transgene free genomes editing approaches. These genome editing tools can improve the desired traits precisely and efficiently. Moreover, a newly developed breeding method "Speed Breeding" has revolutionized the agriculture by shortening the crop cycle. It can produce 5-6 generations of cereals in a year. In this review, we have summarized all these conventional and molecular breeding approaches to improve the cereal crops.
\end{abstract}

Keywords: Plant breeding, Genome editing, molecular breeding, Prime editing, Base editing, CRISPR Cas, Epigenetics, Speed breeding.

\title{
Introduction:
}

With the burgeoning human population, the demand of food has put a lot of pressure on the agricultural system. It has been estimated that in the next 50 years, agricultural system needs to double up the production of food to feed more than 9 billion people ${ }^{1}$. Most of the cereal crops are staple food with approx. $66 \%$ contribution to the food supply worldwide. The rise in population will require $38-67 \%$ increase in cereals production, i.e., rice, maize and wheat ${ }^{2}$. Both conventional and molecular breeding approaches have been used to increase the production of cereal crops.

With the progress in molecular biology and plant breeding, (Figure 1) various new genome editing tools (CRISPR/Cas9, CRISPR/Cpf1, prime editing, base editing, epigenetic modification tool) are available to edit the plants genome precisely, efficiently, and in less time $^{3}$. Meganucleases (MNs), zinc-finger nucleases (ZFNs), transcription activator-like effector nucleases (TALENs), CRISPR/Cas9 and CRISPR/Cpf1 use the double-stranded DNA break (DSB) at the targeted sites to cleave the DNA and insert a donor DNA. The repairing machinery of the cell repairs the cleavage site by non-homologues end joining (NHEJ) or homology directed repair (HDR) ${ }^{4}$ (Figure 2). Moreover, there are a few genomes editing tools 
(GE) that work independently without inducing the double stranded DNA breaks (DSB), including prime editing, base editing and dCas9 based epigenetic modification. These genome editing tools (GE) can be responsible for the unwanted DNA mutations. Furthermore, transgenic events are regulated and approved by Food and Drug Administration (FDA), Environmental Protection Agency (EPA) and United States Department of Agriculture Animal $\&$ Plant Health Inspection Service (USDA/APHIS). ${ }^{5}$. A conventional breeding process takes almost 8-12 years to develop an improved variety. With the rapidly changing environmental conditions, the newly developed varieties are needed in a short time span.

Meganucleases were the first genome editing tools to improve the maize and wheat genome. Meganucleases are naturally occurring molecular DNA scissors that can recognize up to 12-40 DNA bases. Zinc finger nucleases work on the same pattern as meganucleases and can recognize up to 9-18 base pairs. TALENs have advantage over other site-specific nucleases (Meganucleases and Zinc Finger nucleases) due to its nature that it targets at single nucleotide as compared to three in meganucleases and zinc finger nucleases (ZFN). TALENs were successfully used in many cereal crops ${ }^{6}$. CRISPR/Cas9 and CRISPR/Cpf1 were associated with off target mutations, and this issue was resolved by using the modified genome editing tools such as prime editing, base editing and dCas9 based epigenetic modification ${ }^{7}$. Apart from molecular approaches, an advanced breeding method called "Speed Breeding" was introduced in simple breeding procedure ${ }^{8}$. Speed breeding speeds up the breeding methodologies with short generation period and have refined to achieve up to 6 generations in one year ${ }^{9}$.

In this review, first we discussed about the role of conventional breeding approaches, and then compared it with the new genome editing tools and speed breeding approach for the improvement of cereals. Finally, we have discussed about the applications of these approaches to increase the cereals production. 


\section{History of Molecular Biology \& Plant Breeding}

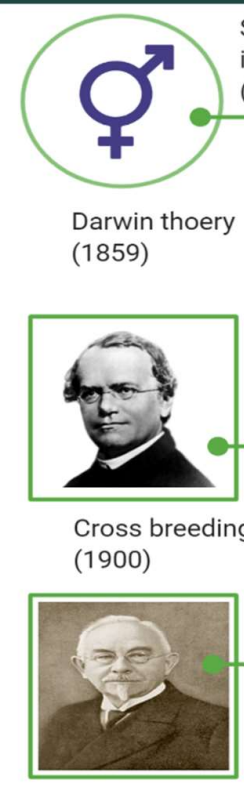

First Maize hybrid (1917)

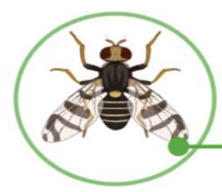

Mutation in Barley (1928)
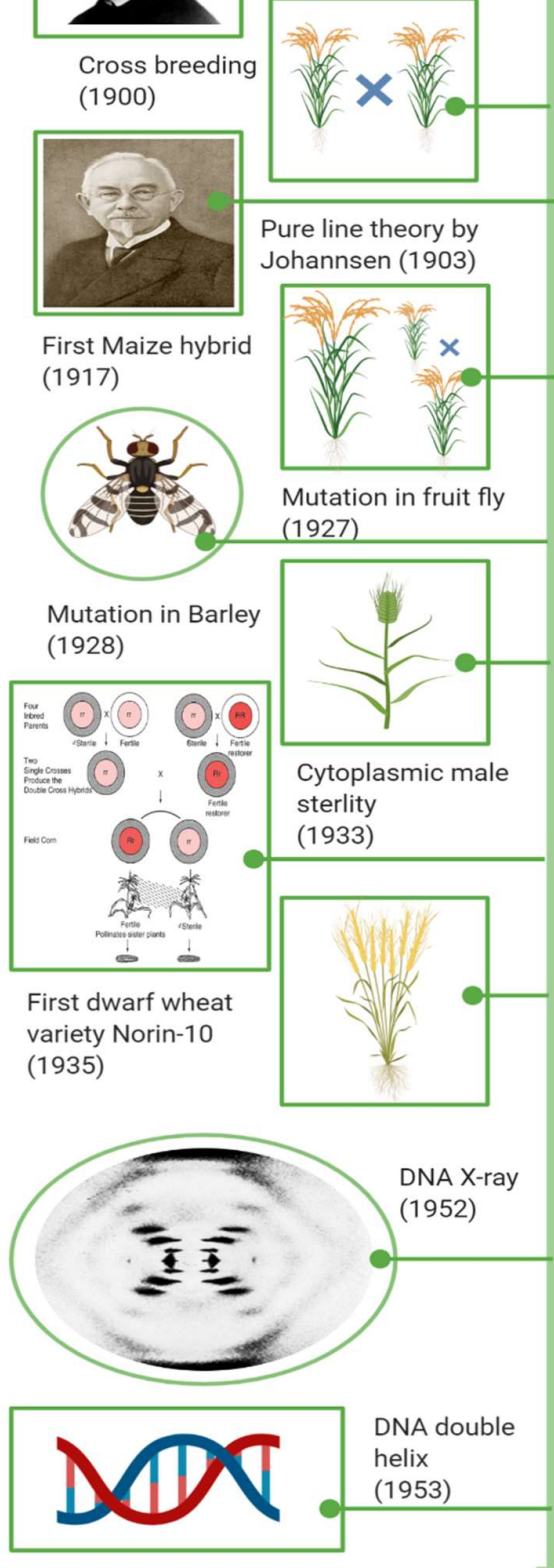

Pure line theory by Johannsen (1903)

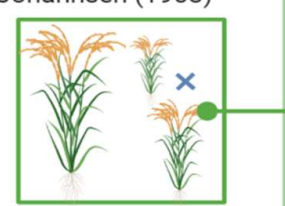

Mutation in fruit fly (1927)
First GMO

tobbaco(1983)
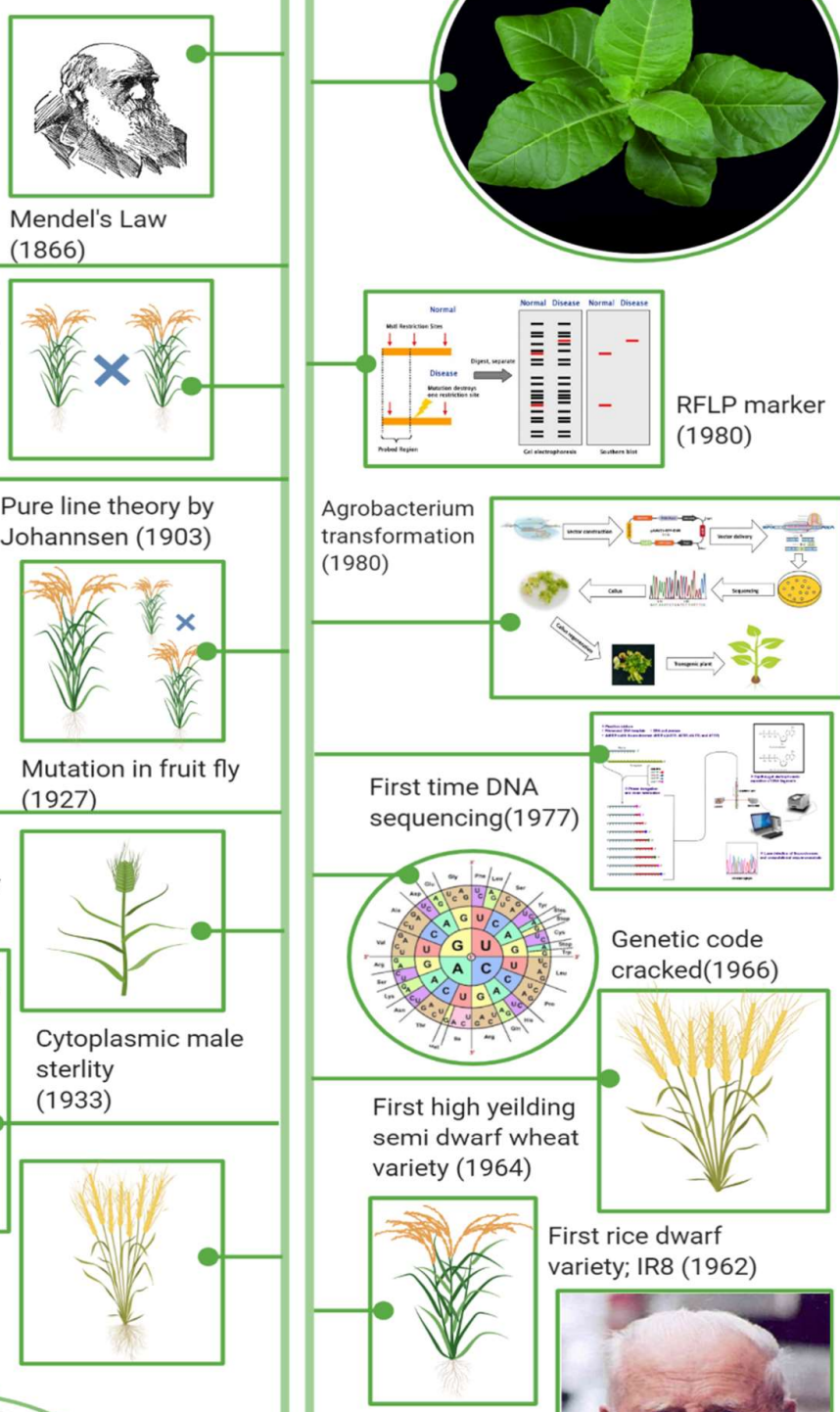

Green Revolution; Norman Borlauge (1960)

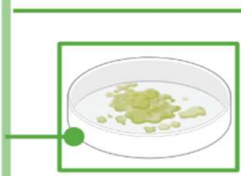

Central dogma

(1957)

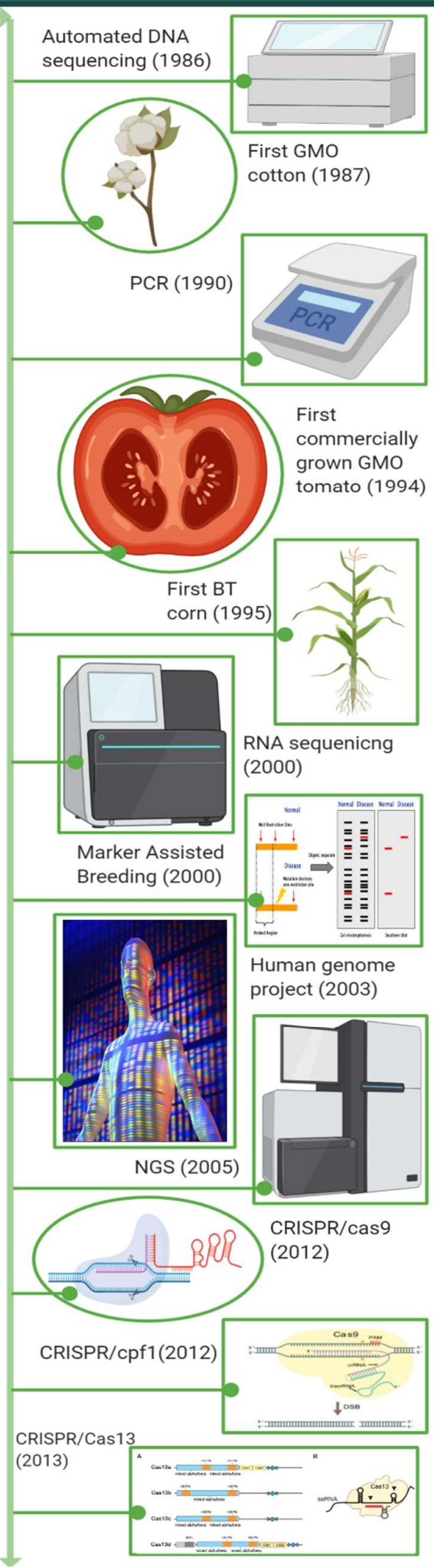

Figure 1: History of molecular biology and plant breeding 

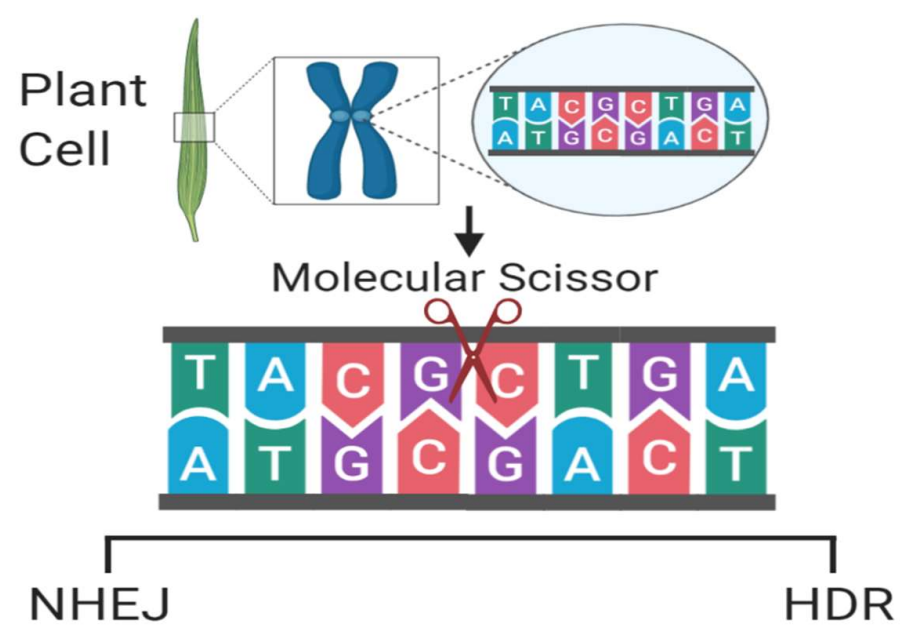

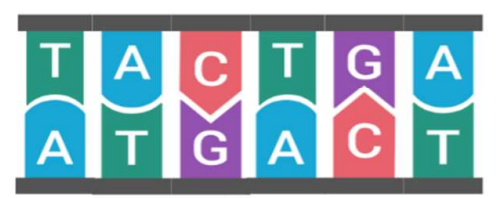

Deletion

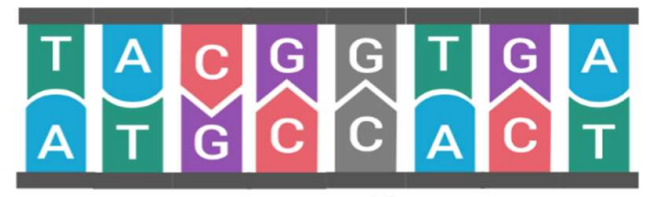

Insertion

Fig 2: In result of GE, two kinds of repairing mechanisms are switched to edit the plant genome (NHEJ and HDR). NHEJ is a non-homology repairing mechanism which can be substituted by insertion or deletion of specific part of genome, naturally. Left is HDR repairing mechanism, can be edited according to our choice, and insert donor DNA

\section{Mutation Breeding (Conventional Breeding) Mechanism and Its Role in Plant Breeding:}

Plant breeding is a technique that is used for the development of superior plants. Its performance depends upon the availability of genetic variations. By making crosses, genetic variability is exploited to transfer it in new varieties ${ }^{10}$. Many other conventional breeding approaches like mutation breeding is also used for the development of new cereal crop varieties $^{11}$.

Mutation causing agents called mutagens are categorized in two categories, namely physical mutagens and chemical mutagens ${ }^{12,13}$. In contrast of physical mutagens, chemicals mutagens are solely used for the point mutation. Physical mutagens (Table 1) is comprised of ionizing radiations which can alter the genetic makeup ${ }^{14}$. 


\begin{tabular}{|c|c|c|c|}
\hline Mutagen name & Source/example & Properties/Mode of action & Effectiveness \\
\hline X-rays & X-ray machine & $\begin{array}{l}\text { Electromagnetic radiation; penetrates tissues from a few millimeters to } \\
\text { many centimeters }\end{array}$ & Penetrating, Dangerous \\
\hline Gamma rays & $\begin{array}{l}\text { Radioisotopes and } \\
\text { nuclear reaction }\end{array}$ & $\begin{array}{l}\text { Electromagnetic radiation produced by radioisotopes and nuclear } \\
\text { reactors; very penetrating into tissues; sources are 60Co (Cobalt-60) } \\
\text { and } 137 \mathrm{Cs} \text { (Caesium-137) }\end{array}$ & Dangerous, very penetrating \\
\hline Neutrons & $\begin{array}{l}\text { Nuclear reactors or } \\
\text { accelerators }\end{array}$ & $\begin{array}{l}\text { There are different types (fast, slow, thermal); produced in nuclear } \\
\text { reactors; uncharged particles; penetrate tissues to many } \\
\text { centimeters; source is } 235 \mathrm{U}\end{array}$ & Very hazardous \\
\hline Beta particles & $\begin{array}{l}\text { Radioactive isotopes or } \\
\text { accelerators }\end{array}$ & $\begin{array}{l}\text { Produced in particle accelerators or from radioisotopes; are electrons; } \\
\text { ionize; shallowly penetrating; sources include } 32 \mathrm{P} \text { and } 14 \mathrm{C}\end{array}$ & May be dangerous \\
\hline Alpha particles & Radioisotopes & $\begin{array}{l}\text { Derived from radioisotopes; a helium nucleus capable of heavy } \\
\text { ionization; very shallowly penetrating }\end{array}$ & Very dangerous \\
\hline Protons & $\begin{array}{l}\text { Nuclear reactors or } \\
\text { accelerators }\end{array}$ & $\begin{array}{l}\text { Produced in nuclear reactors and accelerators; derived from hydrogen } \\
\text { nucleus; penetrate tissues up to several centimeters }\end{array}$ & Very dangerous \\
\hline Ion beam & Particle accelerators & $\begin{array}{l}\text { Produced positively charged ions are accelerated at a high speed } \\
\text { (around } 20 \% 80 \% \text { of the speed of light) deposit high energy on a } \\
\text { target }\end{array}$ & Dangerous \\
\hline
\end{tabular}

Table 1: Physical mutagens

Chemical mutagens (Table 2) are also important for creating point variation in plants genome, but its effects are milder than physical mutegens ${ }^{9}$. The exposure to mutagens causes DNA double strand breaks in plants. Plants have a mechanism to heal the broken strands which can lead to crop improvement. Basically, this phenomenon is the base of improving crops by mutation breeding ${ }^{15}$.

\begin{tabular}{|c|c|c|c|}
\hline Mutagen name & Source/example & Properties/Mode of action & Effectiveness \\
\hline Alkylating agents 1 & $\begin{array}{l}\text { 1-methyl-1-nitrosourea (MNU); 1-ethyl- } \\
\text { 1-nitrosourea (ENU); methyl } \\
\text { methanesulphonate (MMS); ethyl } \\
\text { methanesulphonate (EMS); dimethyl } \\
\text { sulphate (DMS); diethyl sulphate (DES); } \\
\text { 1-methyl-2-nitro-1-nitrosoguanidine } \\
\text { (MNNG);1-ethyl-2-nitro-1 } \\
\text { nitrosoguanidine (ENNG); N, N- } \\
\text { dimethylnitrousamide (NDMA); N, N- } \\
\text { diethylnitrous amide (NDEA) }\end{array}$ & $\begin{array}{l}\text { React with bases and add methyl or ethyl groups and, } \\
\text { depending on the affected atom, the alkylated base may then } \\
\text { degrade to yield a basic site, which is mutagenic and } \\
\text { recombinogenic, or mispair to result in mutations upon DNA } \\
\text { replication. }\end{array}$ & Dangerous, penetrating \\
\hline Azide & Sodium azide & Same as alkylating agents. & Dangerous, very penetrating \\
\hline Hydroxylamine & Hydroxylamine & Same as alkylating agents & Very hazardous \\
\hline Antibiotics & $\begin{array}{l}\text { Actinomycin D; mitomycin C; azaserine; } \\
\text { streptonigrin }\end{array}$ & $\begin{array}{l}\text { Chromosomal aberrations also reported to cause cytoplasmic } \\
\text { male sterility }\end{array}$ & May be dangerous \\
\hline Nitrous acid & Nitrous acid & $\begin{array}{l}\text { Acts through deamination, the replacement of cytosine by } \\
\text { uracil, which can pair with adenine and thus through } \\
\text { subsequent cycles of replication lead to transitions. }\end{array}$ & Very dangerous \\
\hline Acridines & Acridine orange & $\begin{array}{l}\text { Intercalate between DNA bases thereby causing a distortion } \\
\text { of the DNA double helix and the DNA polymerase in turn } \\
\text { recognizes this stretch as an additional }\end{array}$ & Very dangerous \\
\hline
\end{tabular}


5-bromouracil (5-BU); maleic hydrazide; 5-bromodeoxyuridine; 2 aminopurine (2AP) base and inserts an extra base opposite this stretched (intercalated) molecule. This results in frame shifts, i.e. an alteration of the reading frame. replication thereby causing transitions (purine to purine or
Incorporate into DNA in place of the normal bases during DNA pyrimidine to pyrimidine); and tautomerization (existing in two forms which interconvert into each other, e.g. guanine can exist in keto or enol forms)

Dangerous

Table 2: Chemical mutagens

Mutagens were significant players in improving the economy of USA, Japan, China, Pakistan, and India. India is the second highest contributor for improving the crop varieties by exploiting the genetic variation caused by these mutagens ${ }^{16}$. Till 2020 almost 1594 varieties of cereals and 3346 total crop varieties have been developed by using the mutation. Not only in cereal crops, mutation breeding was also employed for other crops too, including fruit crops (apple, citrus, peach) and ornamental plants (chrysanthemum, dahlia, poinsettia) ${ }^{16}$.

\section{Past Achievements of Conventional Breeding in the Improvement of Cereals:}

In cereals many varieties were developed by using the mutation breeding (Fig 5). Cereals are playing their vital role to meet the production needs. Though cereal production is more than other crops however, it is still difficult to meet the production target by 2050 with the continuously increasing population.

Historically, plant breeders were solely using introduction, selection, and hybridization technique to improve the cereals. But, in the present era, mutation breeding is only the solution to create genetic variation instantly in available germplasm. 


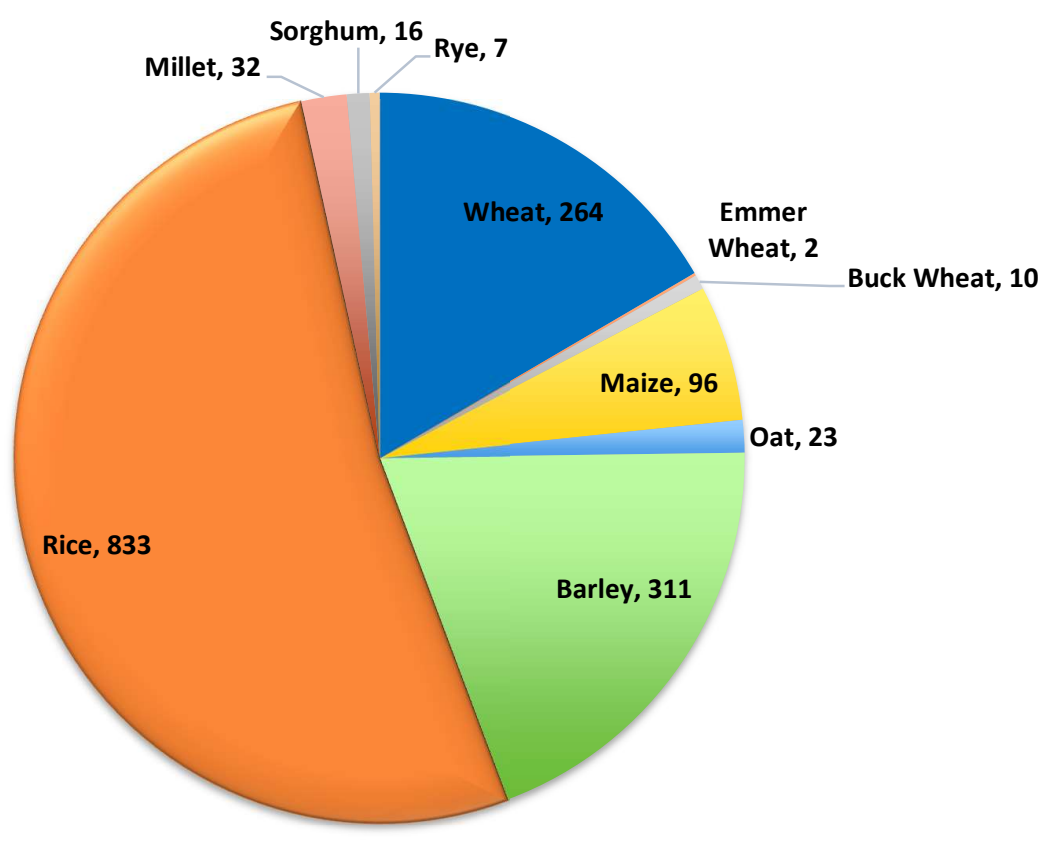

Fig 5: Cereals verities developed by mutation breeding (registered by MVD database)

Up to 2020, many varieties by mutation were released by different countries across the globe (Figure 6). A high yielding wheat variety "Stadler" developed by USA had also showed a dramatic resistance against leaf rust, loose smut, lodging, and also depicted excellent results for early maturity ${ }^{17}$. In Pakistan, the widely cultivated wheat varieties named as Jauhar-78, Soghat-90 and Kiran-95 were also developed by mutation breeding and played a significant improvement in Pakistan's economy ${ }^{18}$.

In past 5 decades, more than 800 rice varieties were developed by inducing mutation, either directly or made crosses with other elite lines. In 1957, China released the first two Rice varieties (KT 20-74 and SH 30-21) ${ }^{19,20}$. Shortly after that Japan released a mutation induced semi dwarf rice variety which played its outstanding performance against loading which lead to significant increase in yield ${ }^{21}$. By using the mutation strategy, Pakistan has developed a rice variety named as "Kashmir Basmati" which was cultivated at a large area due to its characteristics like aroma and resistance against lodging. In both India and Pakistan, mutation breeding has been successfully used to develop many other varieties ${ }^{22}$. In Australia nine varieties were developed by mutation strategy $\mathrm{y}^{23}$. 
Series1
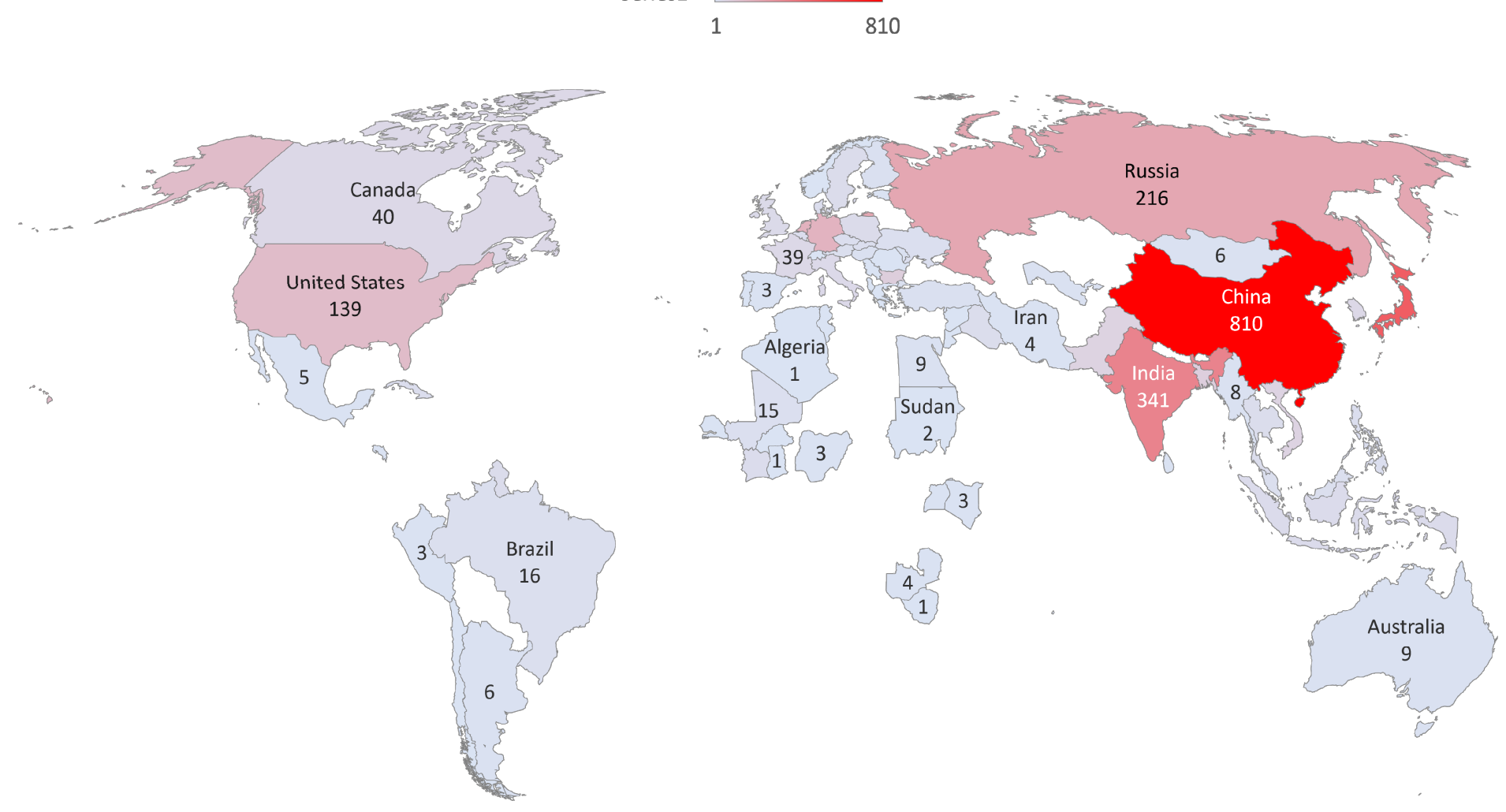

Powered by Bing

Fig 6: Worldwide developed varieties developed by mutation breeding (MVD database)

By using the mutation breeding, a barley variety (Diamant) was developed which also boosted the business of brewing industry in Europe. Centenario mutant variety showed his performance against yellow rust and had high content proteins and yield attributes. Barley mutant named as "Luther" increased the barley yield 20\%. "Pennard" was one of the Barley mutant which showed resistance against hardiness ${ }^{24,17}$. Further details and number of mutant varieties by different countries are available visit the official website (. https://mvd.iaea.org/).

\section{Molecular Breeding Approaches and Its Role in Plant Breeding:}

With the innovation of NGS technology, IT has opened new ways to decipher the genome complexity for the improvement of crops $^{25}$. Genome wide molecular tools (several molecular markers, high density genetic maps, genotyping strategies, etc.) have also played their enormous role in the field of plant breeding ${ }^{26,27}$. Recent genomics innovations have accelerated the breeding methods by using new ways of selection methods which are responsible to screen 
a large data with more precision and efficient breeding (marker assisted selection, association mapping, 'breeding by design', genomic selection, gene pyramiding etc.) Fig 7 ${ }^{27}, 28<$ sup $>29</$ sup $><$ sup $>29</$ sup $><$ sup $>28</$ sup $><$ sup $>29</$ sup $><$ sup $>29</$ sup $><$ sup $>29<1$ $\sup ><\sup >30</$ sup $><$ sup $>29</$ sup $>$.

In the below diagram we have made a comparison between different GE tools (Table 3). Recently, a wide variety of molecular approaches have surfaced.

Fig 7: Transgenic breeding such as CRISPR/Cas9 GE tool take 4-5 years to develop a transgenic crop.

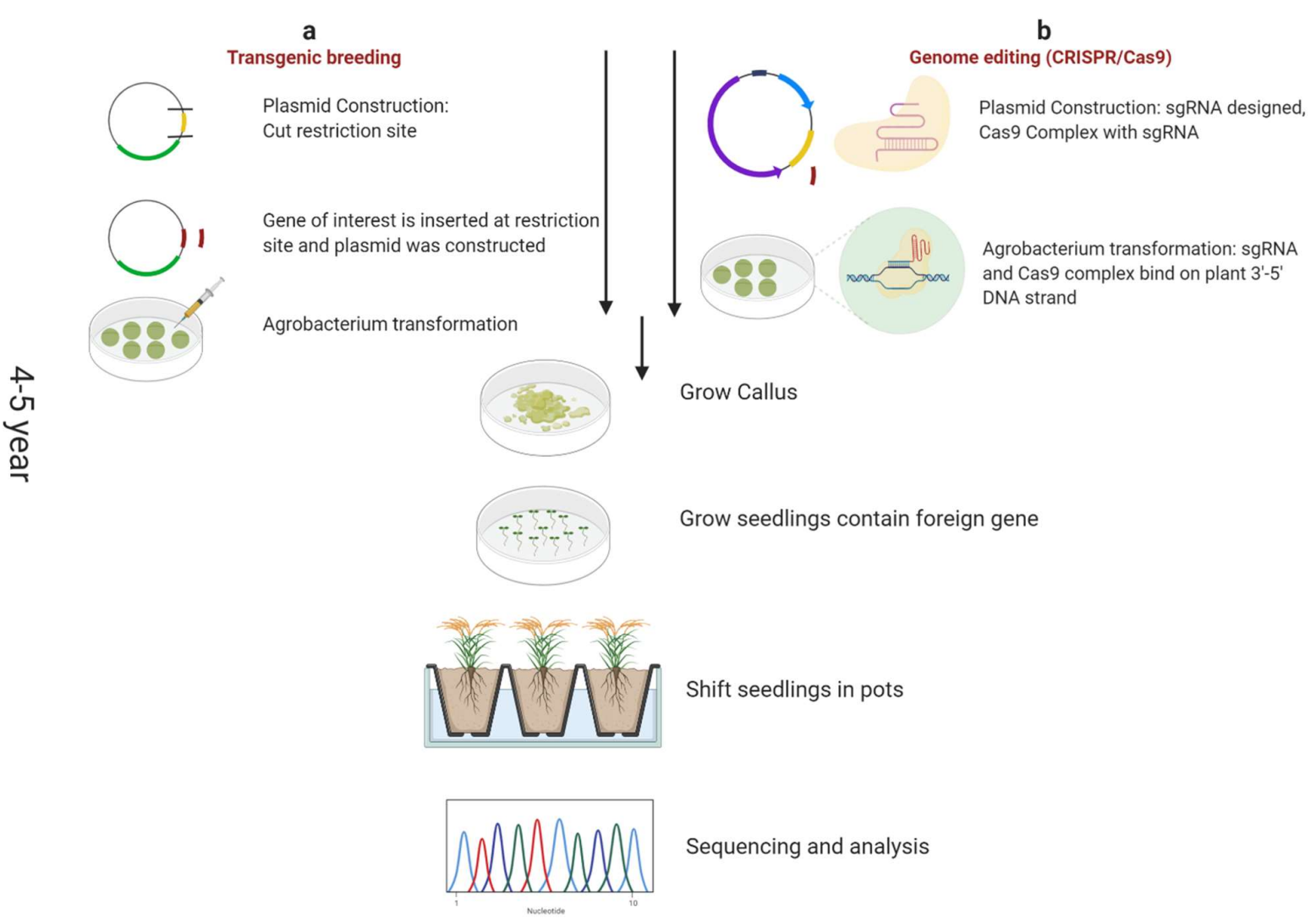

NGS is 1000 times more cheaper than Sanger sequencing which generates vast array of genomic information ${ }^{30}$. The bottleneck of NGS is the collection of information about the genome, and further bioinformatics analysis has identified important QTLs, regulatory sequences and several molecular markers ${ }^{31}$.

In the field of plant breeding, several molecular approaches like MNs, ZFN, TALENS (Figure 8), CRISPRcas9, CRISPRcasf1 are used for the crop's improvement with more specificity and efficiency $^{32,2,33}$. 


\section{Meganucleases Mechanism}

SSN (site-specific nucleases) is one of the gene editing tools which can cleave the DNA in a predetermined fashion. Usually, these SSNs have specific DNA binding domain or RNA sequence which can recognize the specific DNA sites on targeted sequence and cleave it. SSNs are categorized in four classes, named as MegaN, ZFNs, TALENs, CRISPR. Meganucleases are called as DNA scissors which were discovered in late 1980s and are able to recognize and cut large double stranded DNA base pairs of 12-40. Due to long recognition site, it can only occur once in any genome. For example, I-SceI meganuclease recognize 18-BP, and it requires a quite large genome size (20 times more than a human genome) to be found once. Due to their natural occurrence in genome, site specific cleavage and large recognition of DNA bases, meganucleases are considered as very precise restriction enzymes ${ }^{34}$.

In comparison to other SSNs, meganucleases are naturally occurring restriction enzymes with low toxicity effects in cells as compared to ZFNs. The number of identified meganucleases are very low, and further manipulation of meganucleases make it very challenging for molecular biologists to handle it. Therefore, other genome editing tools like ZFNs, TALENS, and CRISPRs can overcome the above stated limitations.

(a) MNs
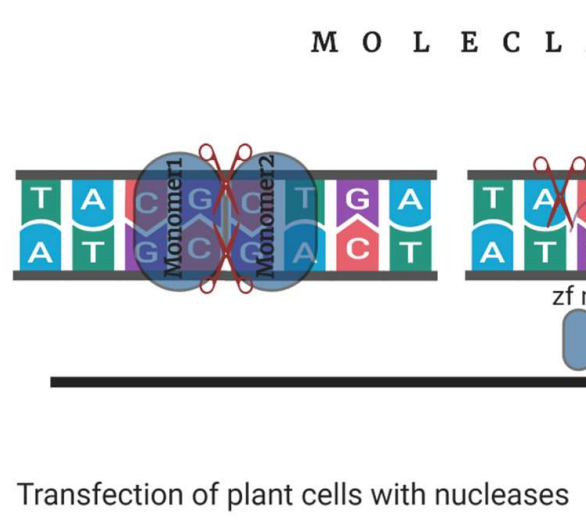

(b) ZFNs

(c) TALENS

Transfection of plant cells with nucleases

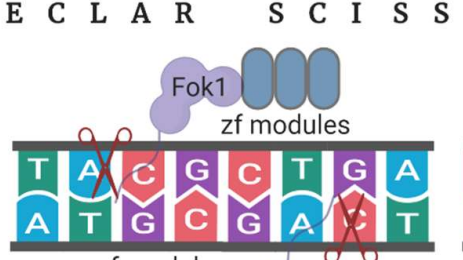
zf modules

Fok1

RVD modules

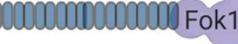

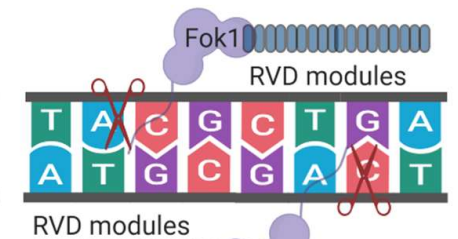

Regeneration system to generate transgenic plants

Identification of induced mutantion

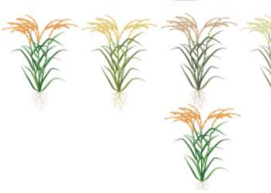

Development of genome edited plants

Fig 8: MNs, ZFN, and TALENs are GE tools also known as molecular scissors to improve the plant genome. (a) meganucleases which can recognize DNA sequences (12-40). Two monomers bind at a specific genome region to work as a endonuclease and cut that part. (b) ZFN which also work as restriction enzyme. ZFN DNA-binding domains (module) contains 
Fok1 nuclease domain which bind in such a manner, cut the genome part between the binding sites. (C) TALENs are consisted of DNA binding and cleavage domains. DNA binding domain is composed of 33-35 repeated amino acids, with divergent 12 th and 13th amino acids. These two variable positions are called as repeat variable di-residues (RVDs). Due to variable in nature, slight change in RVDs can change the targeting efficiency. These RVDs bind at specific region of the genome, along with nuclease domain (Fok1) that cut the specific genome part. In the given diagram, there is a complete procedure to edit the genome by GR tool like $(a, b, c)$.

\section{ZFN Mechanism:}

ZFNs were discovered in 1980s which were the most versatile tool to edit the genome at users defined locations for the improvement of important triats ${ }^{35}$, Limitations of $\mathrm{MgNs}$ are mitigated by employing ZFN tool which is comprised of two domains; DNA binding ( DNA-recognition modules) and DNA cleavage (FokI restriction enzyme) ${ }^{36}$. First time, this genome editing tool was employed to edit the genome in Arabidopsis ${ }^{37}$. Each DNA binding domain is comprised of three to six zinc finger repeats, and can recognize 12-18 nucleotides per ZFN momomer ${ }^{38}$. Each zinc finger repeats contains 30 amino acids which form $\beta \beta \alpha$-fold structure. For cleavage at the specified DNA site, dimerization of two FokI nuclease domains are required. Thus, ZFNs are assembled at both sides of the cleavage site which increases the specificity of ZFNs to cleave at targeted $\operatorname{sites}^{39,40}$.

ZFNs were used for the genome editing of many living organisms, including human ${ }^{41}$, plant ${ }^{42}$, Zebrafish ${ }^{43}$, Drosophila melanogaster ${ }^{43}$, mice $^{44}$, pig $^{45}$, frog ${ }^{46}$, zebrafish, and Caenorhabditis elegans $^{47}$. ZFN has played an enormous role to modify the plants genome, including rice, apple, maize, soybean, petunia, Arabidopsis, Nicotiana, fig, rice, and rapeseed ${ }^{48}, 49$. This genome editing tool can be applied in other plants which can accept the DNA delivery to their genome. For gene stacking, different reliable gene insertion sites have been identified in rice ${ }^{50}$. In another example, ZmIPK1 gene was manipulated by inserting PAT gene that resulted in herbicide tolerance in plants ${ }^{51}$. This genome editing tool was used to create resistance against Tomato yellow leaf curl China virus (TYLCCNV) and Tobacco curly shoot virus (TbCSV) ${ }^{52}$.

\section{TALENS Mechanism:}

Transcription activator-like effector nucleases (TALENS) were developed to edit the plant's genome more efficiently as compared to ZFNs. Journal "Nature method" enlisted TALENS as a method of the year due to its astounding performance for precise genome editing. Developmental history of TALENs, is incomplete without intervention of phytopathogenic Xanthomonas bacteria ${ }^{53,54}$. TALENs are Transcription activator-like effector nucleases proteins which are secreted in the plant's cell machinery via type III secretion system of phytopathogenic Xanthomonas bacteria to bind on $\mathrm{DNA}^{55}$. These phytopathogenic bacteria 
cause lethal symptoms like blights, canker, spots, etc. in different crops, including tomato, rice, and pepper. As a result of secretion in plant's cells, plants become prone to pathogens. Further, research on TALENs confirmed its function to bind on DNA and mimic the eukaryotic transcription factors. By mimicking the transcription factors, TALENs activates the expression of resistance genes ${ }^{54}$.

Like ZFNs, TALENs work in a proximity of DNA binding domain (TALE repeats) and DNA cleavage enzyme (Fok1 cleavage domain) ${ }^{56}$. In contrast to ZFNs, TALEs are comprised of tandem repeats of 33-35 amino acids, and each repeat targets only single nucleotide which make it more flexible and precise genome editing tool. Each amino acid repeat is comprised of (RVDs) at positions 12 and 13. In 2009, for the first time, these RVDs were confirmed by Bonas and another group of researchers. Based on RVDs, each amino acids repeat is dictated to specify the single base pair and bind on targeted region ${ }^{57}$. These RVDs are highly variable in their nature so can bind at more than one targeted sites ${ }^{58}$. In pursuance of highly efficient and precise genome editing, these TALE repeats can be engineered to direct the binding of amino acids at specified DNA sequences ${ }^{58}$.

\begin{tabular}{|c|c|c|c|c|c|c|c|}
\hline Functions & EMNs & ZFNs & TALENS & $\begin{array}{l}\text { CRIPSRs/Cas } \\
9\end{array}$ & $\begin{array}{l}\text { Base } \\
\text { Editing }\end{array}$ & $\begin{array}{c}\text { CRIPSR/C } \\
\text { pf1 }\end{array}$ & References \\
\hline $\begin{array}{l}\text { Mode of } \\
\text { action }\end{array}$ & $\begin{array}{l}\text { In the target region } \\
\text { direct conversion of } \\
\text { information stand }\end{array}$ & $\begin{array}{l}\text { In the target region } \\
\text { double-strand } \\
\text { breaks }\end{array}$ & $\begin{array}{l}\text { In the targeted DNA } \\
\text { region double-strand } \\
\text { breaks }\end{array}$ & $\begin{array}{l}\text { In the targeted } \\
\text { DNA region } \\
\text { double-strands } \\
\text { or dingle strand } \\
\text { breaks }\end{array}$ & $\begin{array}{l}\text { Single } \\
\text { Stranded } \\
\text { Base } \\
\text { changing }\end{array}$ & $\begin{array}{l}\text { Double } \\
\text { stranded } \\
\text { breaks }\end{array}$ & 59,60 \\
\hline $\begin{array}{l}\text { Target } \\
\text { recognition }\end{array}$ & Good & Good & Good & Good & $\begin{array}{l}\text { Very } \\
\text { Good }\end{array}$ & Very Good & 60,61 \\
\hline Mutation rate & Average & High & Average & Low & Low & High & $60,62,59,33$ \\
\hline $\begin{array}{l}\text { Creation of } \\
\text { large-scale } \\
\text { libraries }\end{array}$ & Difficult to do & Impossible & Difficult to do & Possible & Possible & Possible & $60,63,64$ \\
\hline Multiplexing & $\begin{array}{l}\text { Technically } \\
\text { difficult }\end{array}$ & Hard to do & Hard to do & Possible & Possible & Possible & $60,65,59,66$ \\
\hline Components & $\begin{array}{l}\text { Exogenous } \\
\text { polynucleotide } \\
\text { (chimeraplast) }\end{array}$ & $\begin{array}{l}\text { Zn finger } \\
\text { domains } \\
\text { Nonspecific } \\
\text { FokI } \\
\text { nuclease } \\
\text { domain }\end{array}$ & $\begin{array}{l}\text { TALE } \\
\text { DNA-binding } \\
\text { domains } \\
\text { Nonspecific } \\
\text { FokI } \\
\text { nuclease } \\
\text { domain }\end{array}$ & $\begin{array}{l}\text { Cas9 } \\
\text { proteins, } \\
\text { crRNA }\end{array}$ & $\begin{array}{l}\text { CBEs, } \\
\text { ABEs }\end{array}$ & $\begin{array}{l}\text { Cpf1 } \\
\text { proteins, } \\
\text { crRNA }\end{array}$ & $\begin{array}{l}60,61,67, \\
68\end{array}$ \\
\hline $\begin{array}{l}\text { Structural } \\
\text { protein }\end{array}$ & Dimeric protein & $\begin{array}{l}\text { Dimeric } \\
\text { protein }\end{array}$ & Dimeric protein & $\begin{array}{l}\text { Monomeric } \\
\text { Protein }\end{array}$ & $\begin{array}{l}\text { Monome } \\
\text { ric } \\
\text { Protein }\end{array}$ & $\begin{array}{l}\text { Monomeric } \\
\text { Protein }\end{array}$ & 33,59 \\
\hline $\begin{array}{l}\text { Catalytic } \\
\text { Domain }\end{array}$ & $\begin{array}{l}\text { Absence of a } \\
\text { catalytic } \\
\text { domain }\end{array}$ & $\begin{array}{l}\text { Restriction } \\
\text { endonuclease } \\
\text { FokI }\end{array}$ & $\begin{array}{l}\text { Restriction } \\
\text { endonuclease FokI }\end{array}$ & RuvC and $\mathrm{HNH}$ & & $\begin{array}{l}\text { RuvC and } \\
\mathrm{HNH}\end{array}$ & $67 \cdot 60$ \\
\hline
\end{tabular}




\begin{tabular}{|c|c|c|c|c|c|c|c|}
\hline $\begin{array}{l}\text { Length of the } \\
\text { target } \\
\text { sequence (bp) }\end{array}$ & $68-88$ & $24-36$ & $24-59$ & $20-22$ & $\begin{array}{l}\text { Point } \\
\text { Mutatio } \\
\mathrm{n}\end{array}$ & $20-24$ & $63,68,69,33$ \\
\hline $\begin{array}{l}\text { Protein } \\
\text { engineering } \\
\text { steps }\end{array}$ & Not required & Required & Required & $\begin{array}{l}\text { Not } \\
\text { difficult to test } \\
\text { gRNA }\end{array}$ & & $\begin{array}{l}\text { Not } \\
\text { difficult to } \\
\text { test } \\
\text { gRNA }\end{array}$ & $60,64,70$ \\
\hline Cloning & Unnecessary & necessary & necessary & Unnecessary & & $\begin{array}{l}\text { Unnecessar } \\
\text { y }\end{array}$ & $60,64,70$ \\
\hline $\begin{array}{l}\text { gRNA } \\
\text { production }\end{array}$ & Not essential & Can’t Apply & Can't Apply & $\begin{array}{l}\text { Can produce } \\
\text { easily }\end{array}$ & & $\begin{array}{l}\text { Can easily } \\
\text { be produced }\end{array}$ & ${ }^{60},{ }^{64},{ }^{71}$ \\
\hline $\begin{array}{l}\text { Target } \\
\text { genome-editing } \\
\text { tools }\end{array}$ & Not essential & $\begin{array}{l}\text { ZFN Genome } \\
\text { v2.0 ZifBASE } \\
\text { Zinc-Finger } \\
\text { Database } \\
\text { (ZiFDB) Zinc- } \\
\text { Finger Tool } \\
\text { EENdb }\end{array}$ & $\begin{array}{lr}\text { TALE-NT } & 2.0 \\
\text { SPATA } & \text { TALEN } \\
\text { offer } & \text { TALEN } \\
\text { Library } & \end{array}$ & $\begin{array}{l}\text { CHOP CHOP } \\
\text { CRISPRs web } \\
\text { Server Crass: } \\
\text { The CRISPR } \\
\text { Assembler } \\
\text { CRISPR Target }\end{array}$ & $\begin{array}{l}\text { Cas } \\
\text { nickase, } \\
\text { Cpf1 } \\
\text { adenosin } \\
\text { e } \\
\text { deamina } \\
\text { ses, } \\
\text { Cas13b }\end{array}$ & $\begin{array}{l}\text { Breaking- } \\
\text { Cas } \\
\text { Cas- } \\
\text { OFFinder } \\
\text { CRISPOR } \\
\text { CCTOP }\end{array}$ & $68,70,72$ \\
\hline $\begin{array}{l}\text { Off-target } \\
\text { effects }\end{array}$ & $\begin{array}{l}\text { Low off-target } \\
\text { effect }\end{array}$ & $\begin{array}{l}\text { Low off-target } \\
\text { effect }\end{array}$ & $\begin{array}{l}\text { Shows least } \\
\text { off-target } \\
\text { activities }\end{array}$ & $\begin{array}{l}\text { Low off-target } \\
\text { effect }\end{array}$ & $\begin{array}{l}\text { Very } \\
\text { Low }\end{array}$ & $\begin{array}{l}\text { Low off- } \\
\text { target effect }\end{array}$ & 60,62 \\
\hline $\begin{array}{l}\text { Cost of } \\
\text { development }\end{array}$ & High & High & Higher & Low & Low & Low & $60,63,64$ \\
\hline
\end{tabular}

Table 3: Comparisons between different GE tools

\section{CRISPR/Cas based Genome Editing (with DSBs):}

\section{CRISPR from yogurt to Plant Breeding:}

It took more than a decade to understand the mechanism of Cas9 and its function as endonuclease to edit the genome which was thought to be due to the mysterious repetitive sequences, later named as CRISPR (clustered regularly interspaced short palindromic repeats) (Figure 8). CRISPR loci is composed of Cas genes, repetitive sequences interspaced by variable sequences (spacers) which are corresponding to the sequences present in foreign genetic elements called as protospacers (Figure 9). Cas9 genes translate themselves in proteins and degrade the genome of foreign genetic element. While, CRISPR array are transcribed into shorter CRISPR RNAs (crRNAs) but most of the CRISPR arrays are initially transcribed in a single $\mathrm{RNA}^{73}$. CRISPR was named for the repeated sequences and for the common associated genes present is clusters that were adjacent to the repeated sequences were labelled as "Cas" genes $^{74}$. Further, it was observed that the viruses that infect bacteria shares some similarities with the sequences present between the repeats. The Cas genes were also identified having the ability to cut DNA by encoding domains of proteins ${ }^{75}$. These associated genes serves the basis of classifying CRISPR into 3 different types (I,II, III) ${ }^{76}$. The type I and III have different Cas 
proteins that also form complexes with CrRNA (CRISPR RNA) in order to assist the target nucleic acids identification and destruction ${ }^{77}$. The type II has a smaller number of Cas proteins and their biological importance is still elusive ${ }^{78}$. The type II led the basis of genome editing techniques.

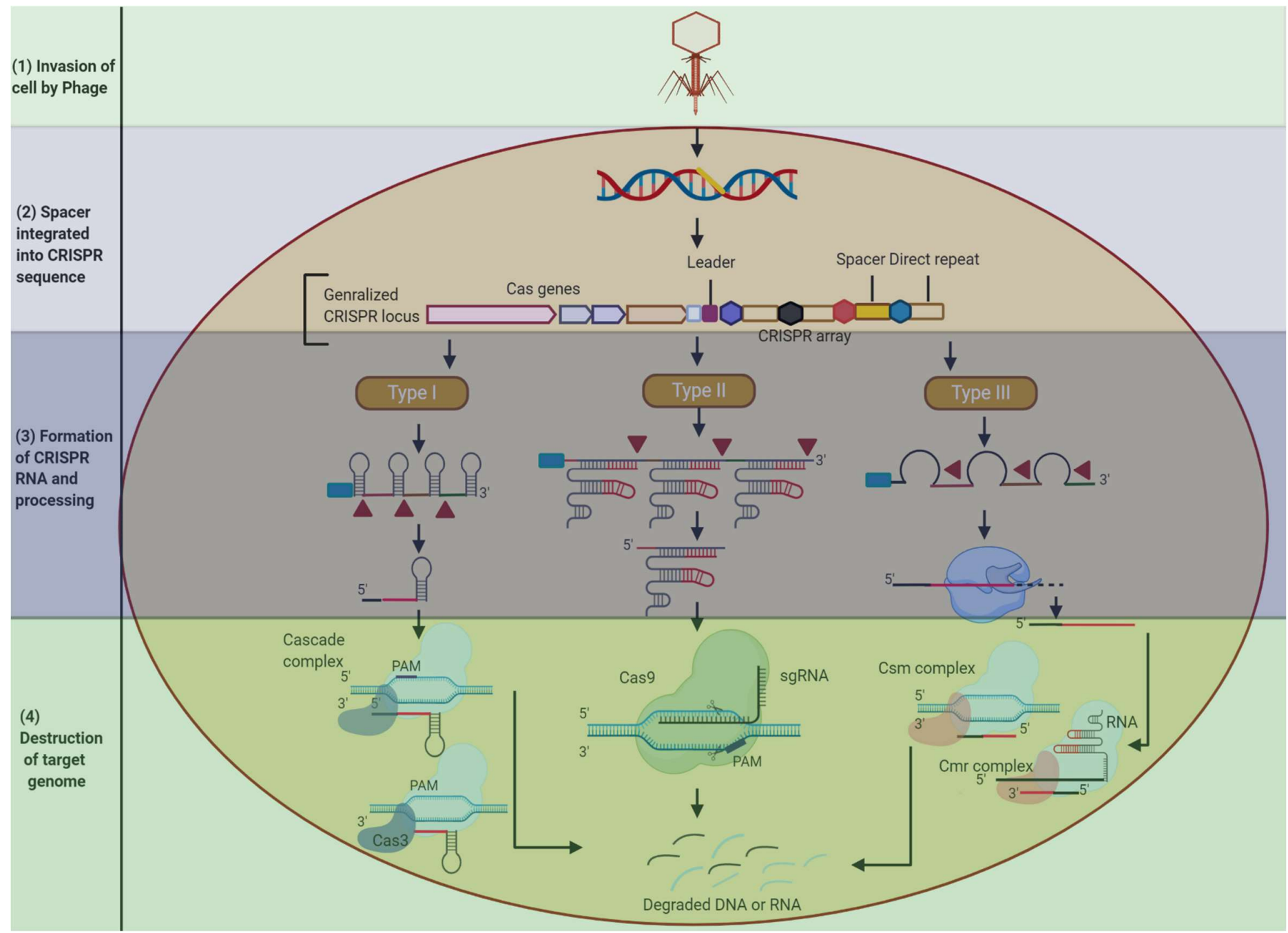

Figure 8: Schematic mechanism of bacterial CRISPR system as a defensive tool to degrade the viral genome. During the invasion (step 1: invasion of virus) foreign genetic material (virus) enters bacteria acquire spacers inside their genome and save it to recognize in future invasion and found between direct repeats. (step 2: spacer integration in CRISPR locus). CRISPR array is a noncoding part which is maturated and work only according to specific CRISPR system (step 3: CRISPR RNA formation and processing). In CRISPR type I and III, associated ribonucleases in CRISPR work to cleave the pre crRNA between the repeats and liberate many short crRNAs. System III associated crRNA further goes through a process at 3'end by employing the RNases which are yet to be identified and produce maturated RNA transcript. (Step 4: Destruction of target genome). For the recognition and destruction of the target sites, the type I and III has several complexes of proteins with crRNAs. The cascade complex is present in type I and Csm and Cmr complexes are present in type III for DNA and RNA cleavage, respectively. The cas 3 nuclease bounded with the R-loop facilitates the process in type I. whereas, the type II has less proteins and cas9 is required for degradation. Protospacer adjacent motifs (PAMs) in type II facilitates the cas9 in identifying the target sites. In both I and II types, self-targeting of CRISPR is prevented due to the lack of PAM in the targeted sequences. 


\section{History of CRISPR}

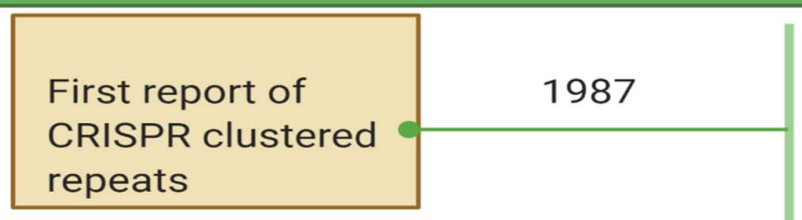

Coined "CRISPR" name and defined signature Cas gene

First experimental evidence for CRISPR adaptive immunity
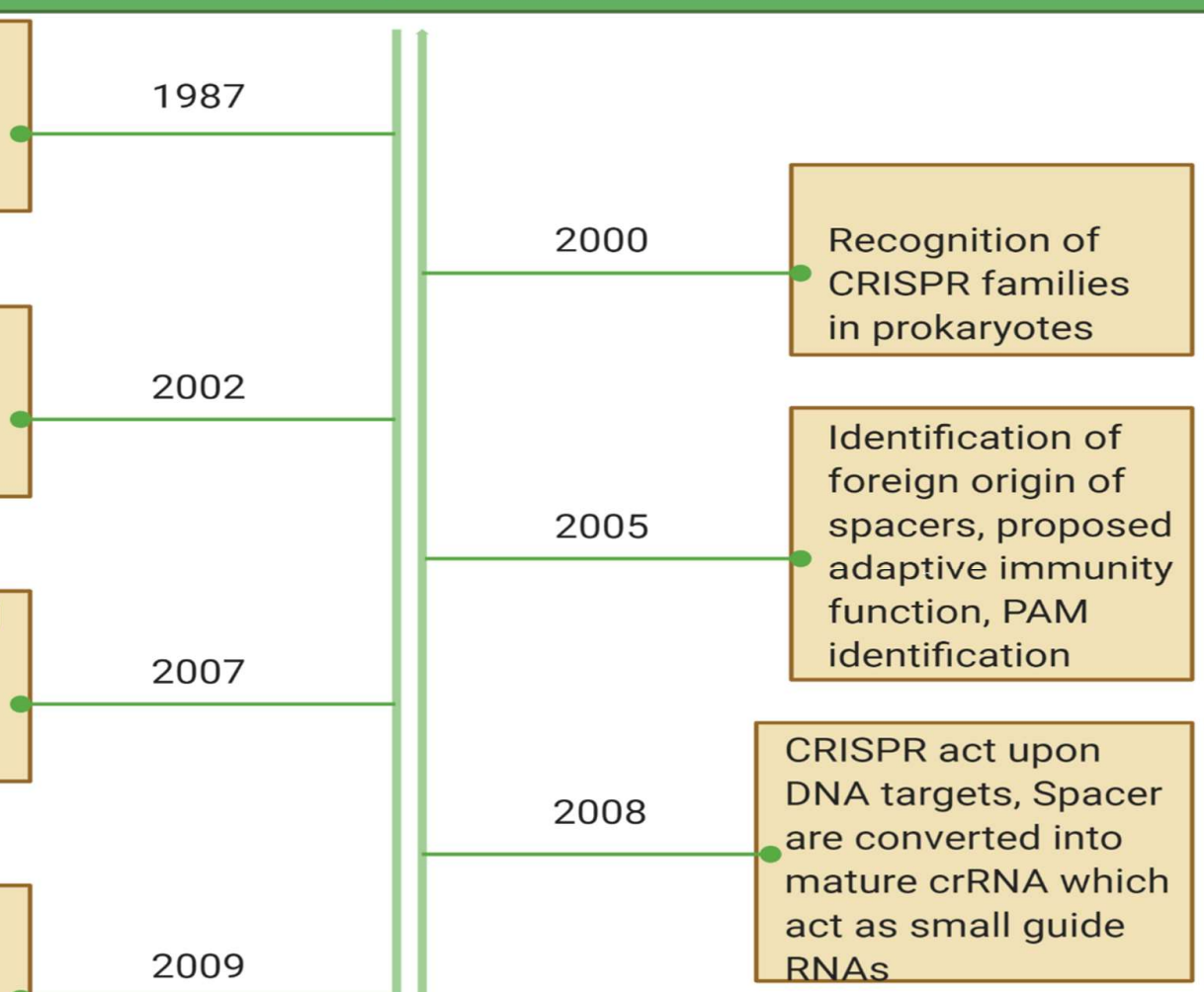

Type III-B Cmr CRISPR complexes cleave RNA

tracrRNA form a
duplex structure with
crRNA in association
with Cas 9
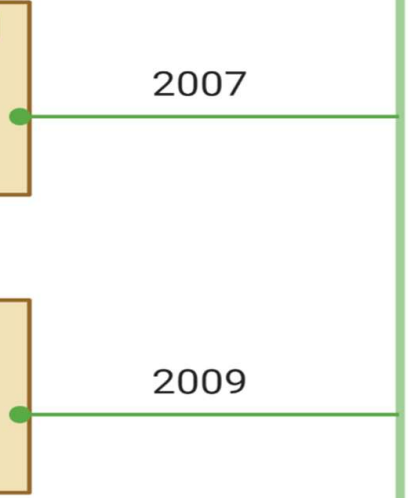

First demonstration of Cas 9 genom engineering in eukaryotic cells

2011

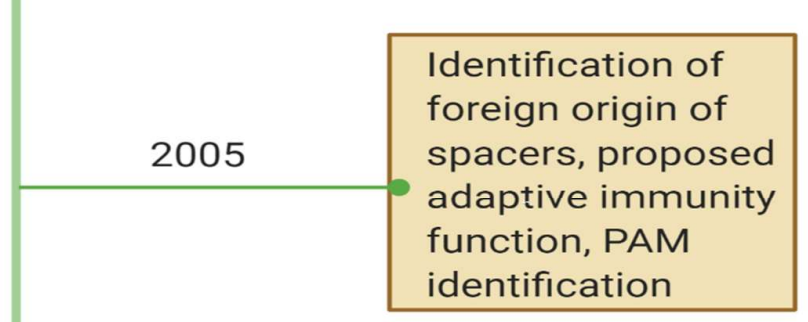

\begin{tabular}{|l|l|}
\hline 2010 & Cas9 is guided by \\
spacer sequences \\
\hline and cleaves target \\
DNA via DSBs \\
\hline
\end{tabular}

\begin{tabular}{|l|l|}
\hline 2012 & $\begin{array}{l}\text { In vitro } \\
\text { characterization } \\
\text { of DNA targeting } \\
\text { by Cas9 }\end{array}$ \\
\hline
\end{tabular}

Genom-wide functional screening with Cas9, Crystal structure of apo-Cas9, Crystal structure of Cas 9 in complex with guide RNA and target DNA 


\section{CRISPR/Cas9 Mechanism:}

The development of CRISPR/cas9 mechanism (Fig 10) for the improvement of crops is associated with the bacterial defensive mechanism, as some bacteria and archaea put into service the CRISPR array to disrupt the viral genome eventually. CRISPR mechanism is performed in three steps: (1) Acquisition step: acquisition of spacer DNA from the viral DNA for which results in the insertion in bacterial genome (to memorize the invading viral DNA); (2) Expression Step: expression of CrRNAs from the transcription of CRISPR array which also involves the expression of the Cas9 protein; (3) Interference Step: CrRNA acts as a guide RNA which is further directed by Cas9 protein to bind at targeted DNA that is accompanied by PAM sites, and cut that specified DNA three nucleotide away from PAM sites at both DNA strands ${ }^{79}$. In result of targeted DNA cleavage, DSBs occur that switches on the repairing mechanism of cell's machinery. Two kinds of mechanisms are switched on: (1) NHEJ; (2) HDR, both are dependent upon the absence and availability of homologues repairing template, respectively. In case of NHEJ, insertions or deletions randomly in independent manners which results in mutations caused by disruption of genes. While, HDR mechanism employ the donor DNA to insert at cleavage site of targeted $\mathrm{DNA}^{79}$.

Bacterial CRISPR/cas9 mechanism edit the plants genome by employing various components, including Cas9 protein, sgRNA. First, sgRNA is designed in silico which is an amalgamation of crRNA and tracRNA. Many computational methods are available online to design the very specific and precise sgRNA, for example CRISPR-P, CHOPCHOP, etc. ${ }^{2,80}$. Its compulsory to construct both expression cassettes of Cas9 and sgRNA, separately. Small nuclear RNA gene promoters $\mathrm{U} 3$ or U6, are used for the transcription of sgRNA by using RNA polymerase 3 and define the initiation and termination site. 
(a) CRISPR/Cas 9

Targetted gene, PAM sites identification

PAM Sites

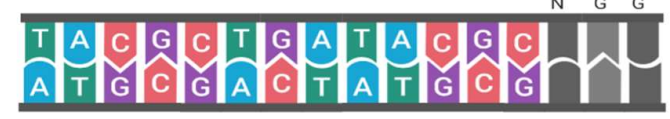

(b) CRISPR/Cpf1

Targetted gene, PAM sites identification
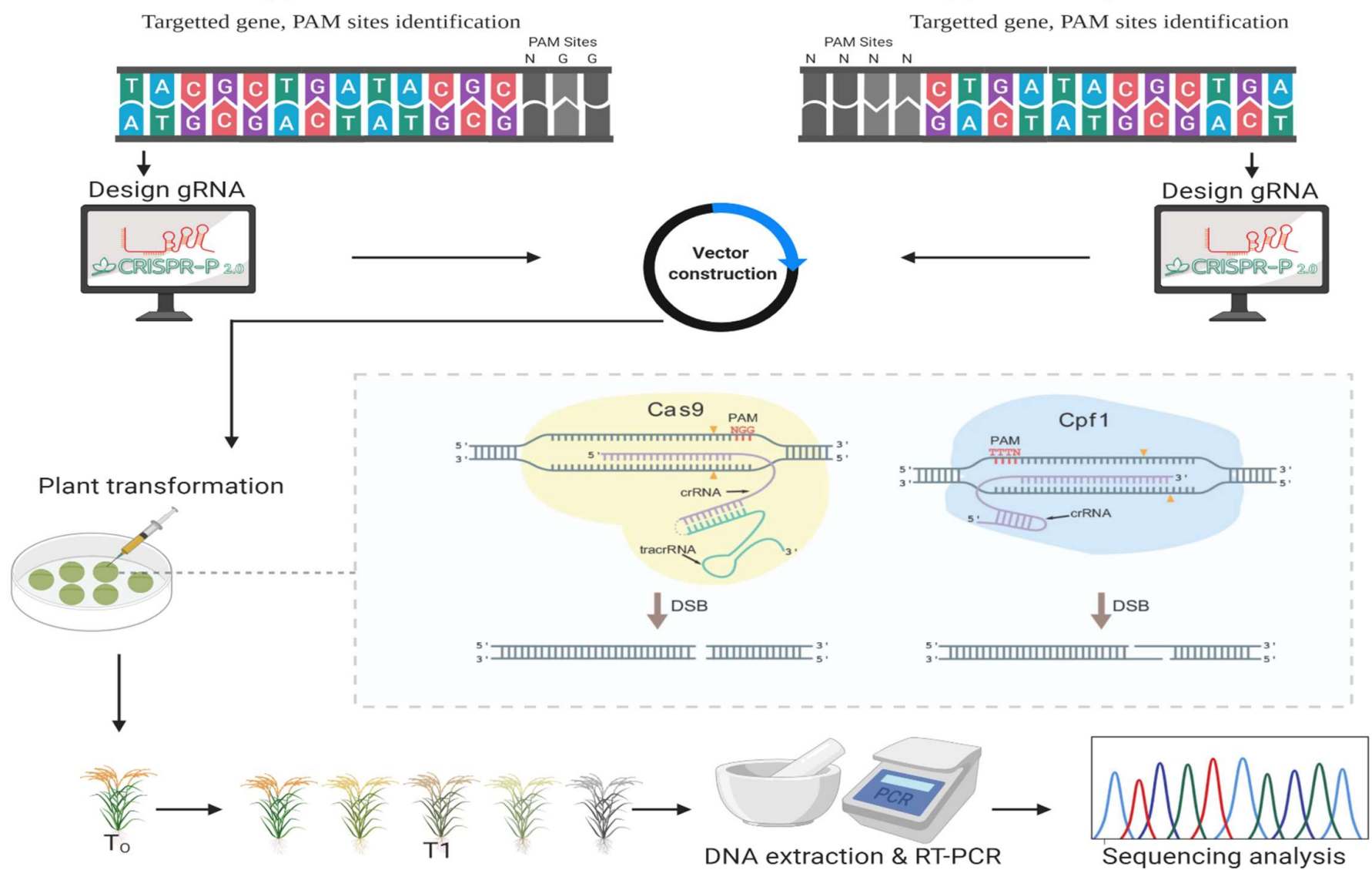

Fig 10: CRISPR/Cas9 and Cpf1 to edit the plant's genome. (a) is schematic of CRISPR/Cas9, while (b) is CRISPR/Cpf1. Both GE tools are used to edit the plant genome. In both GE tools, initially, desired DNA and PAM (20 sequences) sites are selected. Different SgRNA designing bioinformatics tools are available which gives information about the best gRNA for subsequent GE steps. SgRNA is cloned and vector is constructed to deliver in the plant genome by using Agrobacterium tumefaciensmediated plant transformation. By using the couple of steps, transgenic plants are developed. Further transgenic plants are regenerated and screened by genotyping analysis.

For a successful cleavage of specified sites, sgRNA and targeted DNA sequences should be matched, except of first nucleotide ( $5^{\prime} \mathrm{G}$ or A). During the Cas9 expression and its nuclear localization purpose, Single or dual NLS (nucleic localization signal) is fused with Cas9 coding sequence (4107-bp. Both Cas9 and sgRNA expressions cassettes are now assembled in vector to perform further genome editing procedure. Before doing a final genome editing step, protoplasts are transformed with the CRISPR to analyze and validate the sgRNA activity. Next, PCR or restriction enzyme digestion step is employed to select the active CRISPR. Final vector contains the CRISPR/Cas9 setup which is transformed in the plant cells via Agrobacteriummediated transformation or particle bombardment procedure ${ }^{81}$.

After transformation in plant cell, following steps are carried out: activation of Cas9 proteins, cleavage at targeted sites, production of DSBs. Activation step- involves the gRNA to activate 
the Cas9 protein. Without binding of gRNA, Cas9 protein is nonfunctional. Bacteria (Streptococcus pyrogens) has a protein named as Cas9 (originally called as SpCAS9) is widely used in the plants which has uniqueness to recognize the NGG type PAM site.

\section{CRISPR/Cpf1 Mechanism:}

CRISPR/Cas9 technique (Figure 10) is being continuously improved for the efficient genome editing. CRISPR is categorized into two classes; 1 and 2, and further these classes are divided into six subtypes. CRISPR/Cpf1 (Cas12a) refers as CRISPR from Prevotella and Francisella1. CRISPR/Cpf1 was adapted more than CRISPR/Cas9 due to short sgRNA nucleotide length, and reduced size of $\mathrm{Cpf1}$ protein. Its sgRNA only requires shorter crRNA as compared to both crRNA, tracRNA in CRISPR/Cas9 mechanism ${ }^{82,83}$. Its sgRNA directs the Cpf1 nuclease to bind at targeted region upstream of PAM. In comparison to Cas9 protein, Cpf1 prefer T rich PAMs instead of G, and cleaves the targeted DNA at the proximal site of PAM in a staggered fashion to generate blunt ends ${ }^{84}$. CRISPR/Cpf1 has been used in many plants ${ }^{85}$. Furthermore, it is necessary to insert or delete the nucleotide sequences for the improvement of crop traits. For this purpose, naturally repairing mechanism of cell machinery is switched on. Generally, HDR and NHEJ nucleotide repairing mechanism works to insert the nucleotide sequences precisely at cleavage site or random insertion/deletions, respectively ${ }^{86}$.

\section{Genome Editing without DSBs and Donor Template:}

CRISPR-Cas9 is very versatile tool to edit the plant's genome precisely and with efficacy. Despite of its countless services for the betterment of plant genome, it may cause harmful mutations owing to off target effects. These mutations may leave unpredictable results in the next generations There are ways to detect these off target mutations: in-vitro and in-vivo like CIRCLE-seq, GUIDE-seq, DISCOVER-seq, SITE-seq, and Digenome-seq ${ }^{87}$. These mutations result due to DSBs production. Now, brave approaches are being used without induction of DSBs (Figure 11) 88,89 to insert the genome at targeted DNA.

These new approaches like base editing ${ }^{90}$ and prime editing ${ }^{91}$ exploit the Asp10Ala and His840Ala mutations containing dCas9 protein with other effector proteins to bind at specified genome location. It can alter the single base pair without any cleavage of that region ${ }^{92}$. This dCas 9 protein has no more nuclease activity but work to guide the sgRNA for binding. 

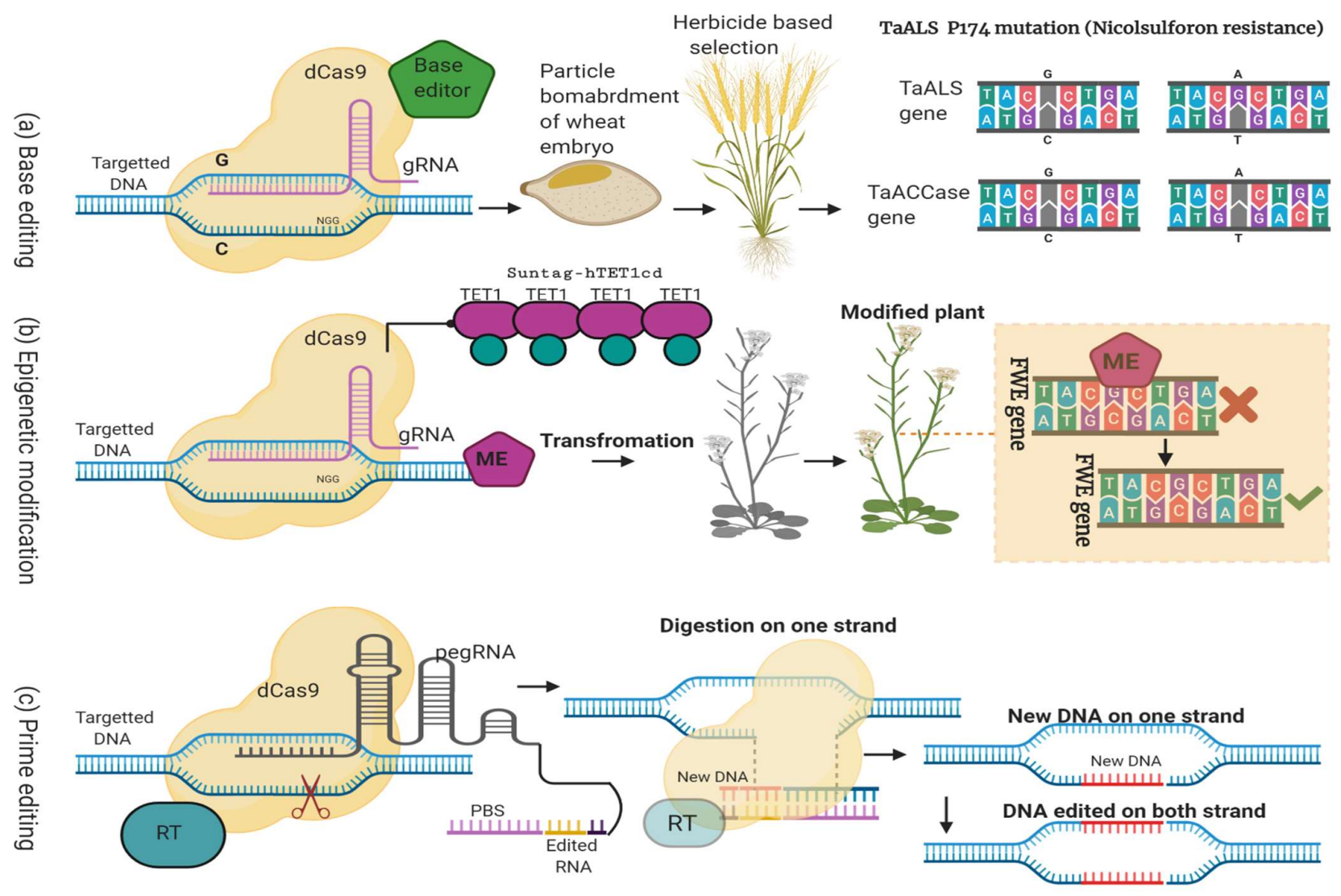

Fig 11: Genome editing without DSBs. Generally, three kinds of GE approaches are being used to edit the plant genome without producing double stranded breaks; a, b, and c (Base editing, Epigenetic modification and Prime editing. In (a) by using the base editing approach, two genes (TaALS and TaACCase) were co-edited. This approach was used by coupling the dCas 9 with Cytosine base editor (CBE). In this way such type of transgenic wheat plants were developed which did not produce any DSBs. (b) is Epigenetic editing. In this approach, dCas9-Suntag-hTET1cd was coupled with dCas9 for demethylation of FWA promoter to activate the FWA gene expression. (c) Prime editing, it works by developing a complex interaction between pegRNA, Cas9 nickase-reverse transcriptase (RT) and target DNA. In the pegRNA, except of primer binding site (PBS), desired genome sequence is also present which is introduced in the host genome. For RT, pegRNA produces primer. RT copies the information of pegRNA, and RT product is integrated in the target genome site. Initially, modification happens only at one target DNA strand. Later, it is present on both strand due to cell's repairing mechanism.

\section{Base Editing:}

Precise genome editing requires gRNA, Cas9 protein, donor template, repairing mechanism for the editing of genome. While, base editing use the reprogrammable deaminase intending to introduce the bases at targeted site without any cleavage and induction of $\mathrm{DSBs}^{93}$. Nowadays, CBE (cytosine base editor) and ABE (adenine base editor) have been developed to alter the C$\mathrm{T}$ and A-G, respectively ${ }^{87}$. In human, daily Spontaneous hydrolytic deamination causes conversion of C-T, A-G, 500 times per cell ${ }^{94}$. By doing the point mutations, diseases and specific traits can be improved. ABE contains different base editors, including Target-AID and 
BE. In Target-AID, pmCDA protein is fused with dCas9 protein (Cas9n, D10A) to perform base editing. In BE series rAPOBEC protein is used for fusing with dCas9 protein (Cas9n, $\mathrm{D} 10 \mathrm{~A}) . \mathrm{CBE}$ is used to alter the $\mathrm{C}-\mathrm{T}$, and then $\mathrm{T}$ is changed to $\mathrm{U}$ in response of natural repairing mechanism. CBE genome editing technique has been already used in crops: tomato, wheat, rice, maize and Arabidopsis. While, $\mathrm{ABE}$ is used to deaminase A to $\mathrm{G}$, and reported in wheat, rice, Arabidopsis, and Brassica napus ${ }^{87}$.

\section{Epigenetic Editing:}

Epigenetic refers to modification of genome without perturbing the DNA sequences such as histone modification, DNA methylation, DNA demethylation, gene imprinting, chromatin remodeling etc. ${ }^{95}$. These modifications are common in plants ${ }^{96}$. Nature has blessed the plants with a specialized mechanism of epigenome editing to protect against various kinds of biotic and abiotic stresses ${ }^{97}$. CRISPR/Cas component Cas9 protein is exploited in the form of dCas9 for the epigenetic modification. Protein dCas9 is fused with the epigenetic modifier for the targeted modification which results in alteration of gene expression ${ }^{92}$. For example, GallegoBartolomé and his colleague worked to modify the plant genome epigenetically by involving DNA demethylation/methylation which results in targeted DNA methylation, and late flowering phenotype was developed ${ }^{92}$. However still it is not clear either epigenetic modification is maintained in next segregates or not. Still, a lot of work is needed to explore this technology.

\section{Prime Editing:}

Prime editing is also a new genome editing technique which utilizes the Cas 9 nickase amalgamated with pegRNA to edit the genome precisely by "search and replace mechanism" In CRISPR/Cas9 mechanism, DSBs are generated which are associated with some complex off target effects, including p53 activation, and translocations. ${ }^{99}{ }^{100}$. First time, prime editing technology was developed by Liu and his colleagues in $2019^{98}$. This technique can perform insertions, deletions, and all bases conversion without requiring donor template and DSBs production. Prime editing system is combined work of Cas9 nickase fusion protein, engineered reverse transcriptase enzyme and a PE guide RNA (pegRNA). This programmable pegRNA is designed to carry the information about the binding sites and replace targeted DNA nucleotides with the desired genetic information ${ }^{98}$. The main objective was to increase its efficiency. To increase the efficiency of prime editing technique, three main developments were done, including prime editor 1 , prime editor 2, and prime editor 3. More research is needed to make 
this technology able for the large number of nucleotide insertions or deletions. However, for small number of nucleotide insertions and deletions, its considered more efficient than CRISPR/Cas9 gene editing tool ${ }^{98}$.

\section{Genome Editing (With DSBs) Role in Cereals Improvement:}

To date, various genome editing tools like MN, ZFNs, TALENSs, CRISPR/Cas9, Cpf1 are being used to improve the plants traits for the biotic and abiotic stress resistances (Table 4a, 4b). CRISPR/Cas9 and Cpf1 based genome editing tools are more efficient than MN, ZFNs, TALENS which represented a major breakthrough in agricultural arena to improve the plants targeted traits with more precision, accuracy, and minimized off target effects ${ }^{87,2,101}$. These genome editing tools are very broad in nature to get it applicable for improvement of cereal crops $^{6}$.

\begin{tabular}{|c|c|c|c|}
\hline Crop & Gene Editing Tool & Targeted Trait & Reference \\
\hline Rice & Cross Breeding & $\begin{array}{l}\text { Increase in number of spikelets per } \\
\text { panicle }\end{array}$ & 102 \\
\hline Rice & Cross Breeding & Increase in Yield & 103 \\
\hline Wheat & Cross Breeding & Increase Grain Yield & 104 \\
\hline Barley & Mutation Breeding & Salt tolerant & 105 \\
\hline Durum wheat & Mutation Breeding & Resistance to black stem rust & 14 \\
\hline Wheat & Mutation Breeding & Resistance to stripe rust & 14 \\
\hline Rice & Mutation Breeding & $\begin{array}{l}\text { Resistance to blast, yellow mottle } \\
\text { virus, bacterial leaf blight and bacterial } \\
\text { leaf } \\
\text { stripe }\end{array}$ & $14 ; 106,20$ \\
\hline Maize & Mutation Breeding & $\begin{array}{l}\text { Resistance against pathogen striga } \\
\text { (Striga asiatica) }\end{array}$ & 106 \\
\hline Rice & Mutation Breeding & $\begin{array}{l}\text { Lodging resistance, acid sulphate soil } \\
\text { tolerance }\end{array}$ & $106,107,20$ \\
\hline Rice & Mutation Breeding & Semi-dwarf cultivar/dwarf & $108,109,110,111,112$ \\
\hline Rice & Mutation Breeding & Early maturity & 113,114 \\
\hline Rice & Mutation Breeding & Adaptation & $109,115,116$ \\
\hline Maize & Mutation Breeding & Acidity and drought tolerance & 117 \\
\hline Rice & Mutation Breeding & Tolerance to cold and high altitudes & $118,119,20$ \\
\hline Rice & Mutation Breeding & Acidity and drought tolerance & 120,121 \\
\hline Rice & Mutation Breeding & Salinity tolerance & 122 \\
\hline Maize & Transgenic Breeding & $\begin{array}{l}\text { Increased vitamin content (vitamins } \mathrm{C} \text {, } \\
\mathrm{E} \text {, or provitamin) }\end{array}$ & 123 \\
\hline Soybean & Transgenic Breeding & Altered carbohydrates metabolism & 124 \\
\hline Barley & Molecular Marker & Adult resistance to stripe rust & 125 \\
\hline Maize & Molecular Marker & Development of quality protein maize & 126 \\
\hline Barley & Cisgenesis & Grain phytase activity & 127 \\
\hline Durum wheat & Cisgenesis & Baking quality & 128 \\
\hline Barley & Speed Breeding & Resistance to Leaf Rust & 8 \\
\hline Rice & Speed breeding & having tolerance to salt stress. & 129 \\
\hline Wheat & Speed Breeding & $\begin{array}{l}\text { Have high protein rate and tolerant to } \\
\text { pre-harvest sprouting }\end{array}$ & 130 \\
\hline Durum Wheat & Speed Breeding & Crown root tolerance & 131 \\
\hline
\end{tabular}




\begin{tabular}{|l|l|l|l|}
\hline Wheat & Speed Breeding & $\begin{array}{l}\text { Resistance to leaf, seminal root number } \\
\text { and angel and plant height. }\end{array}$ & 132 \\
\hline Spring wheat & Speed Breeding & Resistance to Stem Rust & 133 \\
\hline Spring wheat & Speed Breeding & $4-6$ Generation/year & 8 \\
\hline Barley & Speed Breeding & $4-6$ Generation/year & 8 \\
\hline
\end{tabular}

Table 4a: Achievements in cereals by using breeding techniques

\begin{tabular}{|c|c|c|c|c|}
\hline Crop & Gene Editing Tool & Targeted Gene & Targeted Trait & Reference \\
\hline Wheat & CRISPR/Cas9 & TaLOX2 & Development of grain & 134 \\
\hline Maize & CRISPR/Cas9 & $\begin{array}{l}\text { LIG1, Ms } 26 . M s 45 \text {, } \\
\text { ALS1 and ALS2 }\end{array}$ & chlorsulfuron-resistant & 135 \\
\hline Rice & CRISPR/Cas9 & $\begin{array}{l}\text { GS3, GW2, GW5, } \\
T G W 6\end{array}$ & Improved grain related parameters & 136 \\
\hline Wheat & CRISPR/Cas9 & Gli-2 loci & low-gluten foodstuff & 137 \\
\hline Rice & CRISPR/Cas9 & $O s P R X 2$ & Improved salt tolerance level & 138 \\
\hline Wheat & CRISPR/Cas9 & TaInox, TaPds & Chlorophyll synthesis & 66 \\
\hline Rice & CRISPR/Cas9 & Waxy & Enhanced glutinosity & 139 \\
\hline Rice & CRISPR/Cas9 & $H d 2, H d 4, H d 5$ & Early heading & 140 \\
\hline Maize & CRISPR/Cas9 & $P P R, R P L$ & Reduced zein protein & 141 \\
\hline Maize & CRISPR/Cas9 & ARGOS 8 & Drought tolerance & 142 \\
\hline Rice & CRISPR/Cas9 & OsNAC041 & Salt tolerant & 143 \\
\hline Maize & CRISPR/Cas9 & ZmHKT1 & Salt tolerant & 144 \\
\hline Rice & CRISPR/Cas9 & $L A Z Y 1$ & Tiller-spreading & 145 \\
\hline Rice & CRISPR/Cas9 & Gn1a, GS3, DEP1 & $\begin{array}{l}\text { Enhanced grain number, larger grain } \\
\text { size and dense erect panicles }\end{array}$ & 146 \\
\hline Wheat & CRISPR/Cas9 & GW2 & $\begin{array}{l}\text { Increased grain weight and protein } \\
\text { content }\end{array}$ & 147 \\
\hline Wheat & CRISPR/Cas 9 & $\begin{array}{l}\text { TaGASR7, TaGW2, } \\
\text { TaDEP1, } \\
\text { TdGASR7(durum wheat) }\end{array}$ & $\begin{array}{l}\text { Grain development, kernal length, } \\
\text { storability and plant height and weight }\end{array}$ & 148 \\
\hline Wheat & CRISPR/Cas9 & TaGW2, TaGASR7 & Grain and kernel length and weight & 149 \\
\hline wheat & CRISPR/Cas 9 & $\begin{array}{l}\alpha \text {-gliadin, gamma- } \\
\text { gliadins }\end{array}$ & Gliadins & 150 \\
\hline wheat & CRISPR/Cas9 & TaLOX2, TaUbill & Grain development & 151 \\
\hline wheat & CRISPR/Cas9 & $\begin{array}{r}\text { TaDREB2, } \\
\text { TaERF3 }\end{array}$ & Drought signaling & 152 \\
\hline wheat & CRISPR/Cas9 & $\begin{array}{l}\text { TaCER9, TaLOX2, } \\
\text { TaGW2 }\end{array}$ & Grain development & 153 \\
\hline wheat & CRISPR/Cas9 & $\begin{array}{l}\text { TaGW2, TaLpx-1, } \\
\text { TaMLO }\end{array}$ & $\begin{array}{l}\text { Kernel width and weight; resistance to } \\
\text { powdery mildew }\end{array}$ & 154 \\
\hline wheat & CRISPR/Cas9 & $\alpha$-gliadin genes & Low-gluten wheat & 137 \\
\hline wheat & CRISPR/Cas9 & TaMs 45 & Male fertility & 155 \\
\hline Rice & CRISPR/Cas9 & OSSWEET13 & Bacterial blight resistance & 156 \\
\hline Rice & CRISPR/Cas9 & SBEIIb & High amylose content & 157 \\
\hline Wheat & CRISPR/Cas9 & EDR1 & Powdery mildew resistance & 158 \\
\hline Rice & CRISPR/Cas9 & OsERF922 & Enhanced rice blast resistance & 159 \\
\hline Rice & CRISPR/Cas9 & OSSWEET13 & Bacterial blight resistance & 159 \\
\hline Maize & CRISPR/Cas 9 & TMS5 & Thermosensitive male-sterile & 160 \\
\hline Rice & CRISPR/Cas9 & OsMATL & Induction of haploid plants & 161 \\
\hline Rice & CRISPR/Cas9 & OsPIN5b and GS3, & High yielding and cold tolerance & 162 \\
\hline
\end{tabular}




\begin{tabular}{|c|c|c|c|c|}
\hline & & OsMYB30 & & \\
\hline Rice & CRISPR/Cas9 & $A L S$ & Herbicide resistance & 134 \\
\hline Rice & CRISPR/Cas9 & $L A Z Y 1$ & Tiller spreading phenotype & 145 \\
\hline Rice & CRISPR/Cas9 & Gn1a, DEP1, GS3 & $\begin{array}{l}\text { Number of grains, erect panicles, } \\
\text { specific for grain size }\end{array}$ & 146 \\
\hline Rice & CRISPR/Cas9 & SBEIIb & High amylose rice & 157 \\
\hline Rice & CRISPR/Cas9 & OsERF922 & Rice Blast Resistance & 156 \\
\hline Rice & CRISPR/Cas9 & OsEPSPS & Glyphosate resistant & 163 \\
\hline Rice & CRISPR/Cas9 & $A L S$ & Herbicide resistance & 161 \\
\hline Rice & CRISPR/Cas9 & $A L S$ & Herbicide resistance & 164 \\
\hline Rice & CRISPR/Cas9 & EPSPS & Herbicide resistance & 163 \\
\hline Rice & CRISPR/Cas9 & $A L S$ & Herbicide resistance & 165 \\
\hline Maize & CRISPR/Cas9 & $A L S$ & Herbicide resistance & 135 \\
\hline Maize & CRISPR/Cas9 & ARGOS8 & Drought stress tolerance & 166 \\
\hline Wheat & CRISPR/Cas9 & $\begin{array}{l}\text { TaMLOA1, TaMLOB1, } \\
\text { TaMLOD1 }\end{array}$ & $\begin{array}{l}\text { Resistance to powdery } \\
\text { mildew }\end{array}$ & 167 \\
\hline Maize & CRISPR/Cas9 & $P D S, I P K I A, I P K$ & Phytic acid content & 168 \\
\hline Rice & CRISPR/Cpf1 & OsEPFL9 & To regulate the stomatal density in leaf & 169 \\
\hline Rice & CRISPR/Cpf1 & OsROC5 and OsDEP1 & $\begin{array}{l}\text { Editing efficiency was compared on } \\
\text { varying temperature }\end{array}$ & ${ }^{170},{ }^{171}$ \\
\hline Maize & CRISPR/Cpf1 & $G L 2$ & $\begin{array}{l}\text { Editing efficiency was compared on } \\
\text { varying temperature }\end{array}$ & 170 \\
\hline Rice & CRISPR/Cpf1 & $D L, A L S, N C E D 1, A O 1$ & Drooping leaf phenotype & 71 \\
\hline Rice & CRISPR/Cpf1 & $O s P D S, O s B E L$ & Heritable mutations & 172 \\
\hline Rice & CRISPR/Cpf1 & $O s R L K, O s B E L$ & lbino phenotype & 173 \\
\hline Maize & CRISPR/Cpf1 & glossy2 & $\begin{array}{l}\text { Efficiency compared with } \\
\text { CRISPR/Cas9 }\end{array}$ & 174 \\
\hline Rice & CRISPR/Cpf1 & $O s P D S, O s G S 3$ & Improved the editing efficiency & 175 \\
\hline Rice & CRISPR/Cpf1 & $\begin{array}{l}\text { OsDEP1, OsROC5, } \\
\text { OsPDS }\end{array}$ & $\begin{array}{l}\text { Tenfold reduction in miR } 159 \mathrm{~b} \\
\text { transcription, transcriptional repression }\end{array}$ & 176 \\
\hline Rice & CRISPR/Cpf1 & $D E P 1, P D S, E P F L 9$ & $\begin{array}{l}\text { Efficient editing at all TTTV PAM } \\
\text { sites }\end{array}$ & 177 \\
\hline Rice & TALENs & OsSWEET14 & Bacterial blight resistance & 178 \\
\hline Wheat & TALENs & TaMLO & Powdery mildew resistance & 167 \\
\hline Maize & TALENs & $Z m G L 2$ & Reduced epicuticular wax in leaves & 179 \\
\hline Rice & TALENs & $O s B A D H 2$ & Fragrant rice & 180 \\
\hline rice & TALENs & $\begin{array}{l}D E P 1, C K X 2, B A D H 2, \\
S D 1\end{array}$ & $\begin{array}{l}\text { Rapid and Efficient Gene Modification } \\
\text { in Rice }\end{array}$ & 181 \\
\hline Maize & TALENs & ZmMTL & Induction of haploid plants & 182 \\
\hline Maize & TALENs & $\begin{array}{l}\text { PDS, IPKIA, IPK and } \\
\text { MRP4 }\end{array}$ & Reduce the phosphorous concentration & 183 \\
\hline Wheat & TALEN & TaMLO & Powdery mildew resistance & 167 \\
\hline Maize & ZFN & PAT & Herbicide resistance & 184 \\
\hline Rice & ZFN & OsQQR & Detection of safe harbor loci Herbicide & 50 \\
\hline Maize & ZFNs & $Z m I P K 1$ & $\begin{array}{l}\text { Herbicide tolerant and phytate } \\
\text { reduced maize }\end{array}$ & 51 \\
\hline Maize & ZFNs & ZmTLP & Trait stacking & 185 \\
\hline Rice & ZFNs & OsQQR & Trait stacking & 50 \\
\hline Maize & MNs & $\lg 1, m s 26$ & Targeted mutation & 186 \\
\hline Maize & MNs & $m s 26$ & Male sterility & 187 \\
\hline
\end{tabular}




\begin{tabular}{|l|l|l|l|l|}
\hline Wheat & MNs & DsRed & Removed selectable markers & 188 \\
\hline
\end{tabular}

Table 4b: Achievements in cereals by using GE tools

\section{Genome Editing (Without DSBs) Role in Cereals Improvement:}

All genome editing techniques have pros and cons. Similarly, CRISPR/Cas9 and other genome editing tools like MNs, ZFNs, TALENs are associated with off targeted mutations, low efficiency, and PAM sites dependence in plants. These limitations can be addressed by using the new developed methods like base editing and prime editing tools which do not require any DSBs for altering the plants genome, and canfurther alleviate the GMOs concerns ${ }^{7}$.

First time, base editing tool was reported in rice by employing the rat cytidine deaminase enzyme APOBEC1 which is fused to the $\mathrm{N}$-terminus of Cas9 nickase protein. In result of fusion with APOBEC1, the Cas9 nickase becomes programmable with the association of gRNA $^{189}$. By using the base editing tool, two rice genes (NRT1.1B and SLR1) were edited to increase the nitrogen use efficiency and reduce height, respectively ${ }^{190,191}$. Same tool was used to induce the point mutation in rice to check the vectors performance and feasibility. Reported research has contained sgRNA-APOBEC1-XTEN-nCas9-UGI vector, and its efficacy was checked on three targets; (P2) in the OSPDS and (S3 and S5) in the OSSBEIIb which encodes phytoene desaturase and starch branching enzyme IIb in rice, respectively. Rice calli was transfected by using the agrobacterium mediated transformation protocol.

Furthermore, targeted sequence can determine the efficiency of vector up to $20 \%{ }^{192}$. According to our understanding various groups used the base editing tool to improve the plants genome $^{193}$.

First time a new DNA free gene editing tool (prime editing) was developed to make it workable for the mammals and yeast ${ }^{98}$. Later, this system was modified to develop the prime editor 2 (pPE2) system for the genome editing in rice. Base editors have also played a profound role to improve the important agronomic traits, including plant height, disease resistance, and flowering time. However, base editors could not meet the challenges like base transversions and insertions in plants genome. While, Prime editing addressed the already existing problems in base editors to increase the efficiency of transgenic plants $^{91}$. Wei et.al employed prime editor 2 (pPE2) system to induce the point mutation at different targeted sites of rice genome. Different genomic sites depicted varying mutations frequencies $(0 \%-31.3 \%)^{91}$. Further, Prime editing tool are being used to edit he plants genome with increased efficiency and efficacy. Still 
a lot of research is needed to make this technology widely available in the agricultural field to improve the important agronomic traits of different crops.

Epigenetic modifications are inheritable in next generation without GMO regulatory concern. Naturally, epigenetic modifications are happened in the plants genome which are considered as non-GMO crops. CRISPR/Cas9 component, Cas9 protein was modified as dCas9 protein to alter the plants genome epigenetically like DNA methylation which can perform the gene silencing, and many other epigenetic modifications ${ }^{87}$. Protein dCas 9 and different modifiers fused to improve the important traits. First time dCas9 system (dCas9-SunTag-TET1) was fused with the human DNA demethylase (TET1cd) to target the $F W A$ gene, and up regulated the expression of $F W A$ gene which demonstrated late flowering of plants in Arabidopsis ${ }^{194}$. However, the same tool can be employed in other cereal crops to cause DNA methylation for modifying the plants genome in pursuance of beneficial agronomic traits without any GMOs regulatory objections.

\section{Developing genome-edited plants free of Transgene:}

Transformation of plants is usually done by tissue culture technique which is time consuming costly and intensive ${ }^{195}$. Another big hurdle is chance of off target mutation ${ }^{196}$. Therefore, transgene free plants are more preferred in order to minimize the effects of off target mutations. The Cas9 gene is undesirable in this regard as the induction of off target mutations are more due to it ${ }^{197}$.

Some countries require the removal or alleviation of transgenes to ease their regulatory concerns. On the basis of these concerns the researchers are trying to develop null segregants and to achieve this targeted mutation through RNPs (ribonucleoproteins) is the most efficient strategy (Figure 12) ${ }^{198,87}$. Another approach that can be used for this purpose is the selection and regeneration of mutant plants without any pressure of precise selection. however, this approach is time taking and laborious with low efficiency rate to obtain the transgene free plants ${ }^{87}$. Some other approaches that can be used for this purpose are discussed below.

\section{Isolate segregants by Mendelian Segregation:}

This is the most common approach to obtain transgene-free plants by isolating the null segregants through Mendelian approach. This involves the selection of the plants based on the antibiotics resistance by using the CRISPR/Cas9 gene cassette. In this approach after the identification of the genome edited plants, the plants are grown to obtain progenies ${ }^{199}$. The 
transgenes are segregated in the progenies according to the law of segregation. Thus, the selected genome edited plants have high chances of less or no transgenes. The screening can be done more efficiently by using PCR and other technologies to identify the Cas9 free plants. However, this approach is time taking and laborious ${ }^{198}$.

\section{Programmed Self- Elimination of transgene plants:}

In order to reduce the time and cost to select the transgenic free plants, in this approach two suicide genes are used for isolating the null segregants ${ }^{200}$. The two genes used in this approach are BARNASE gene which was placed in the control of REG2 promoter and the $2^{\text {nd }}$ gene CMS was placed in control of $35 \mathrm{~S}$ promoter. The BARNASE is a toxic protein having the ability to kill the plant cells. Those embryos that contain transgenes are killed by this gene. The CMS2 gene affects the mitochondrial functions and cause male sterility ${ }^{201}$ however, by using this approach the null segregants can be isolated. However, this approach cannot be used on asexually propagated plants ${ }^{202}$.

\section{Transient CRISPR/Cas9 gene expression by Protoplast:}

Another method to get the null segregant can be achieved by using DNA or mRNA by transient expression of CRISPR/Cas9. Two researchers Anderson and Lin in 2017 and 2018 respectively, isolated the protoplast from potato and 9 other plant species ${ }^{203,204}$. In both research, mutagenesis was achieved, and the vector sequences were observed in $10 \%$ of the potato lines and in $17.2 \%$ of the Nicotiana tobaccum genome edited lines. The problem with using the protoplast method is that it works with specific protocol for each species and the regeneration of plant is limited. Thus, both studies indicate that this method is useful for the isolation of segregants and the regenerated plants by this method did not show any transgene but still the risk of transgene integration persist. Thus, the method needs screening of the plants more efficiently and precisely ${ }^{205}$.

\section{RNP-mediated genome editing:}

Genome editing using RNA is the most reliable method to be used for transgene free plants. The RNA can be transferred to the protoplast through in vitro culture, as the RNA transformation is DNA-free, the transgene free plants can be obtained ${ }^{206}$. The researcher Woo was the first who demonstrated that in plants CRISPR/Cas9 gRNA ribonucleoprotein complex could be delivered to protoplast. The researcher using this methodology obtains result with the efficiency ranges from $8.4 \%$ to $44 \%{ }^{207}$. With time the successful transformation of RNP 
mediated genome editing is reported in apples and grapevine, wheat, maize and rice. The approach proved to succeed with efficiency rate ranges from 4 to $64 \%$ without selection ${ }^{149}$. The efficiency in maize can be increased using selection markers from 2.4 to $47 \%$. A considerable reduction of mutations in off target regions has been observed by using this approach ${ }^{208}$.

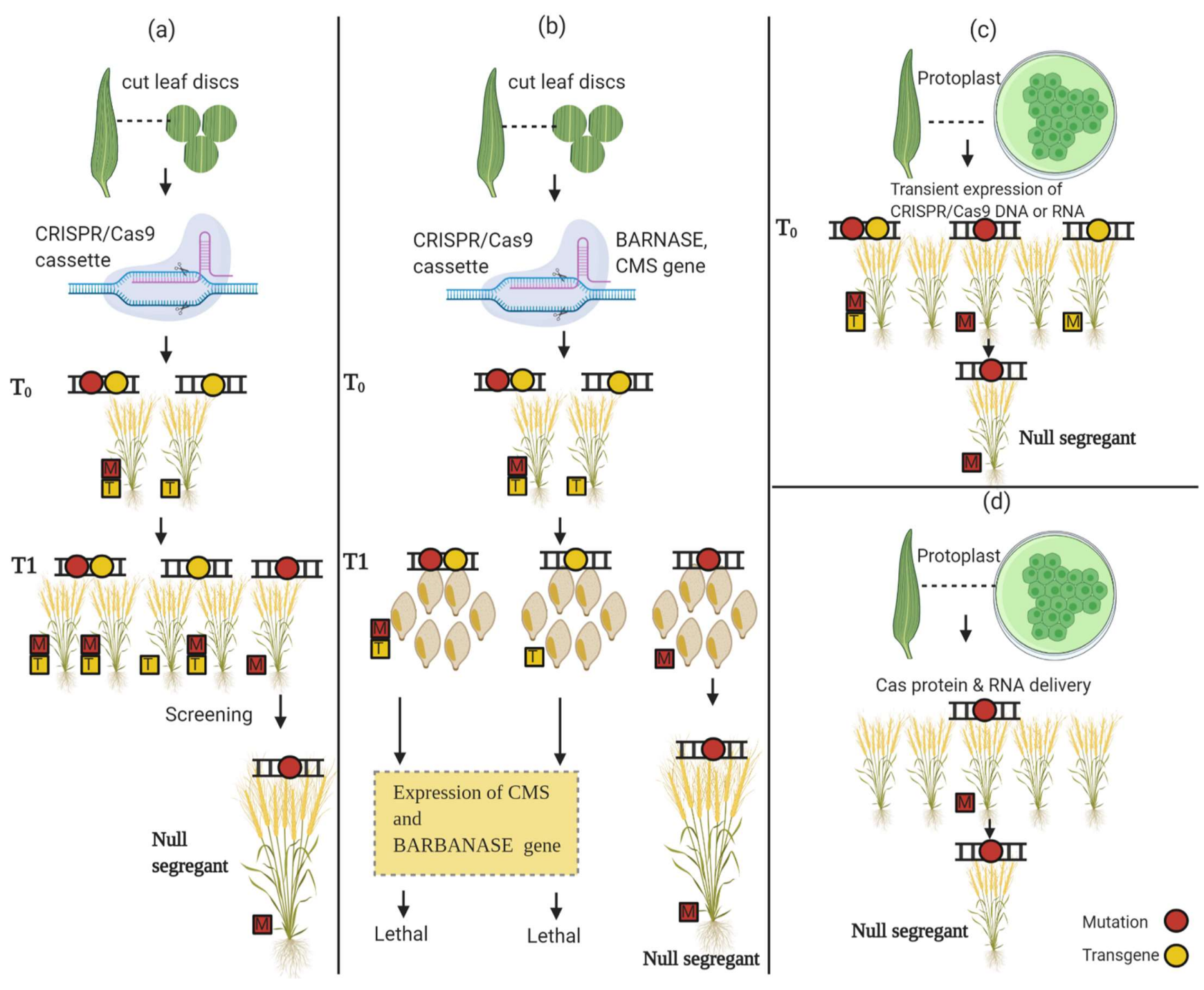

Fig 12: Variety development without transgene by using CRISPR/Cas9. All the possible methods which can be used for developing the null segregants, are present in the above figure as: (a) Isolate segregants by Mendelian Segregation, (b) Programmed Self- Elimination of transgene plants, (c) Transient CRISPR/Cas9 gene expression by Protoplast, (d) RNPmediated genome editing.

\section{Speed Breeding}

Breeding by using conventional breeding methods have shown significant results for many years. Many varieties and lines have been developed by using conventional breeding methods. But, with the passage of time, the dissemination of new improved cultivars is needed with 
substantial increase in production efficiency and disease resistance due to the overgrowing population $^{209}$. Moreover, with the changing climatic conditions the crop production has experienced significant decrease which builds pressure on the researchers to use suitable techniques for crop improvement. Developing varieties with conventional methods takes a lot of time usually $10-15$ years from $1^{\text {st }}$ crossing to variety release ${ }^{210,131}$. This urges the scientists to develop a new methodology to hasten the breeding procedures by reducing the time required to develop new lines, lead to the introduction of a new technique called "Speed Breeding"211.

The speed breeding accelerates the breeding programs by increasing the number of generations per year (Figure 13) ${ }^{8}$. This method was first used on cereal crop "Wheat" by NASA in space by extending the photoperiod with optimum temperature ${ }^{212}$. The continuous lightening allows the plant to grow faster, and the increasing photosynthesis rate boosts up the growth and development. Later on, this method was improved by the scientists of Queensland University by bringing it to the earth and utilizing it in the greenhouses which was then named as Speed breeding, and was $1^{\text {st }}$ practiced on wheat with the purpose to decrease the generational time period. Thus, NASA inspired method to enhance the genetic gain has been reported in boosting the wheat production up to 3 times $^{8}$.

(a)

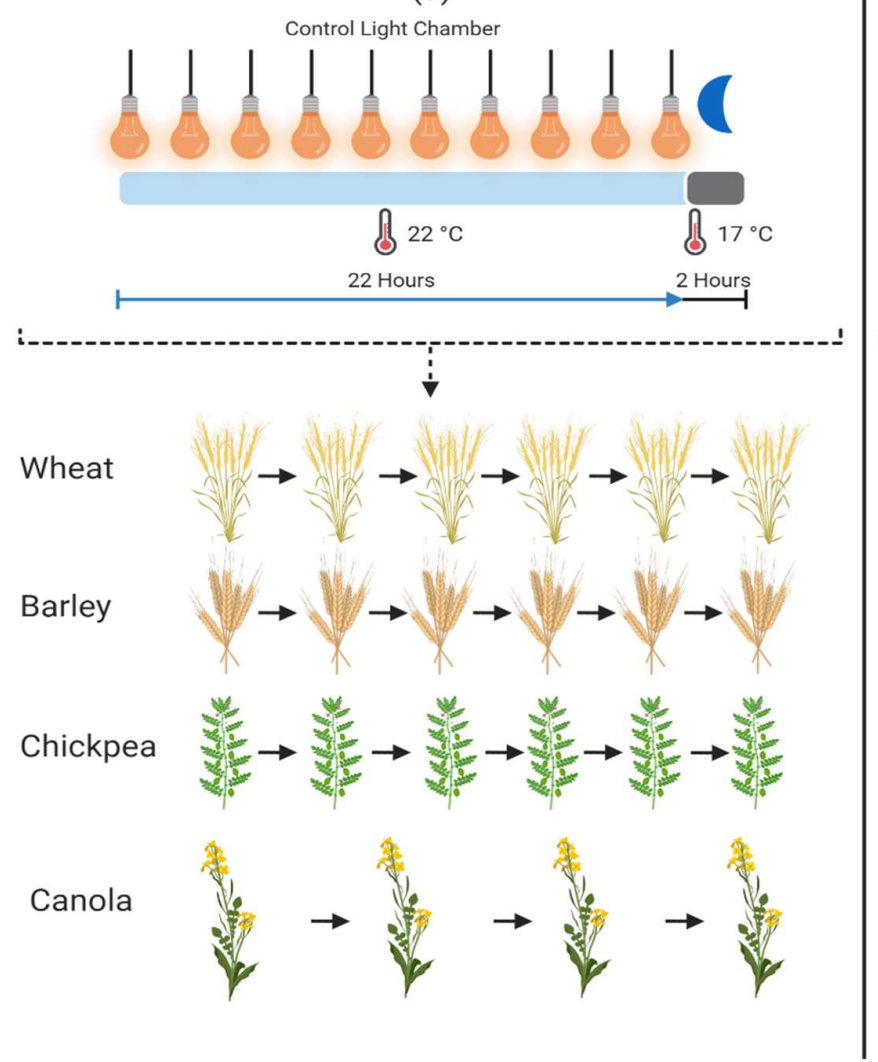

(b)

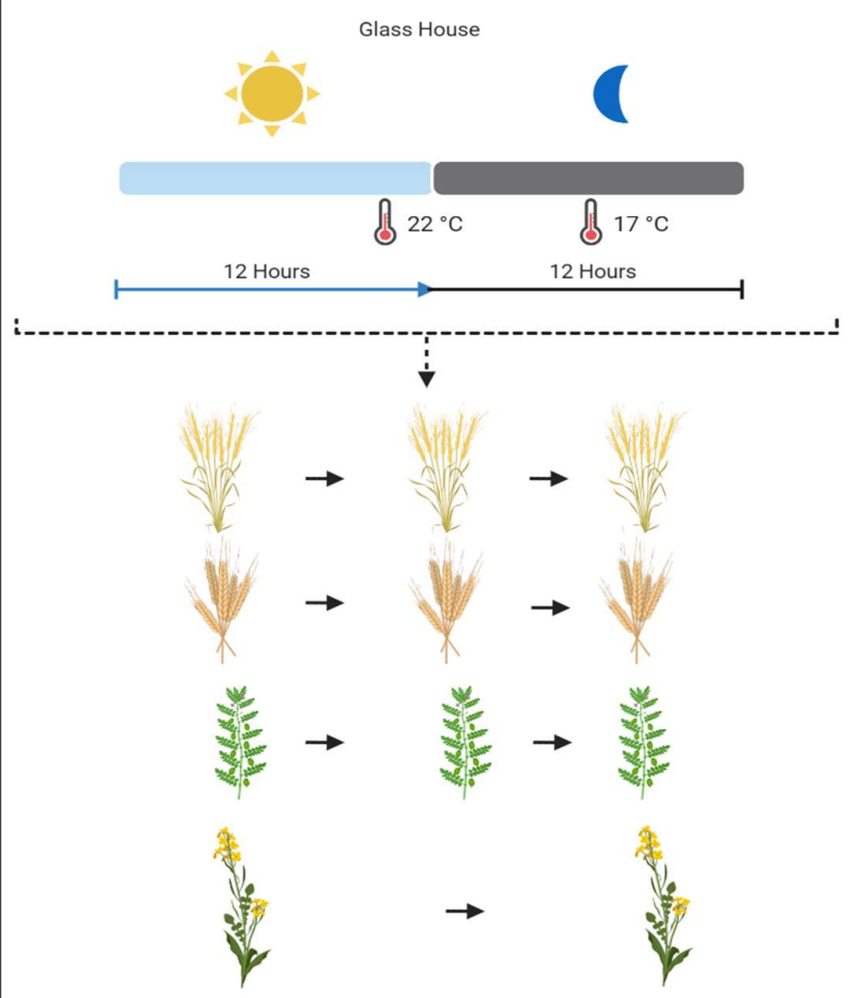

Fig 13: Speed breeding has taken the plant breeding to the next level by getting the 5-6 generation in a year. As compared to glass house (12 hours sunlight, 12 hours dark), speed breeding chamber ( 22 hours artificial light, 2 hours dark) has produced 
the 6 generation of wheat, barley, chickpea, and 4 generation of canola. While, glass house can only produce 3 generations of wheat, barley, canola, and 2 generations of canola. For further detailed explanation of the performed research, refer to section (speed breeding).

\section{Amalgamation of Speed Breeding with GE tools:}

Speed breeding can save the time of generation development by amalgamating it with GE tools. GE tools can only edit one or two non-elite genotypes which is passed through a complex process of transformation and tissue culturing to regenerate the edited plants. Due to the latest innovations, GE tools can edit the elite genotypes with increased transformation efficiency ${ }^{213}, 214$. Instead of massive improvement in GE technology, still it requires complex tissue culturing process and gRNA designing and Cas9 protein recruitment which cannot be performed without molecular lab work ${ }^{215}$. In a new method "ExpressEdit" (Figure 14), by amalgamating the speed breeding with GE tools, most of the invitro manipulations have been bypassed which in result reduces the work pressure in lab and are considered time saving to develop the crop generations ${ }^{1}$. ExpressEdit is a new technique which is carried out by coupling the speed marker assisted selection and preassembled GE tools components (sgRNA and Cas proteins) with speed breeding which can exclude the sensitive callus culturing step ${ }^{1}$. GE tools components like sgRNA and Cas9 protein can be delivered into plant cells (mature seeds, plant shoot apical meristems) by employing the Gemini viruses vectors or direct particle bombardment, for example in wheat ${ }^{216,217}$. In a nutshell, speed breeding with other additions as stated above, can keep pace of crops improvement in the persistent global challenges like ever increasing population and low food production ${ }^{1}$. 


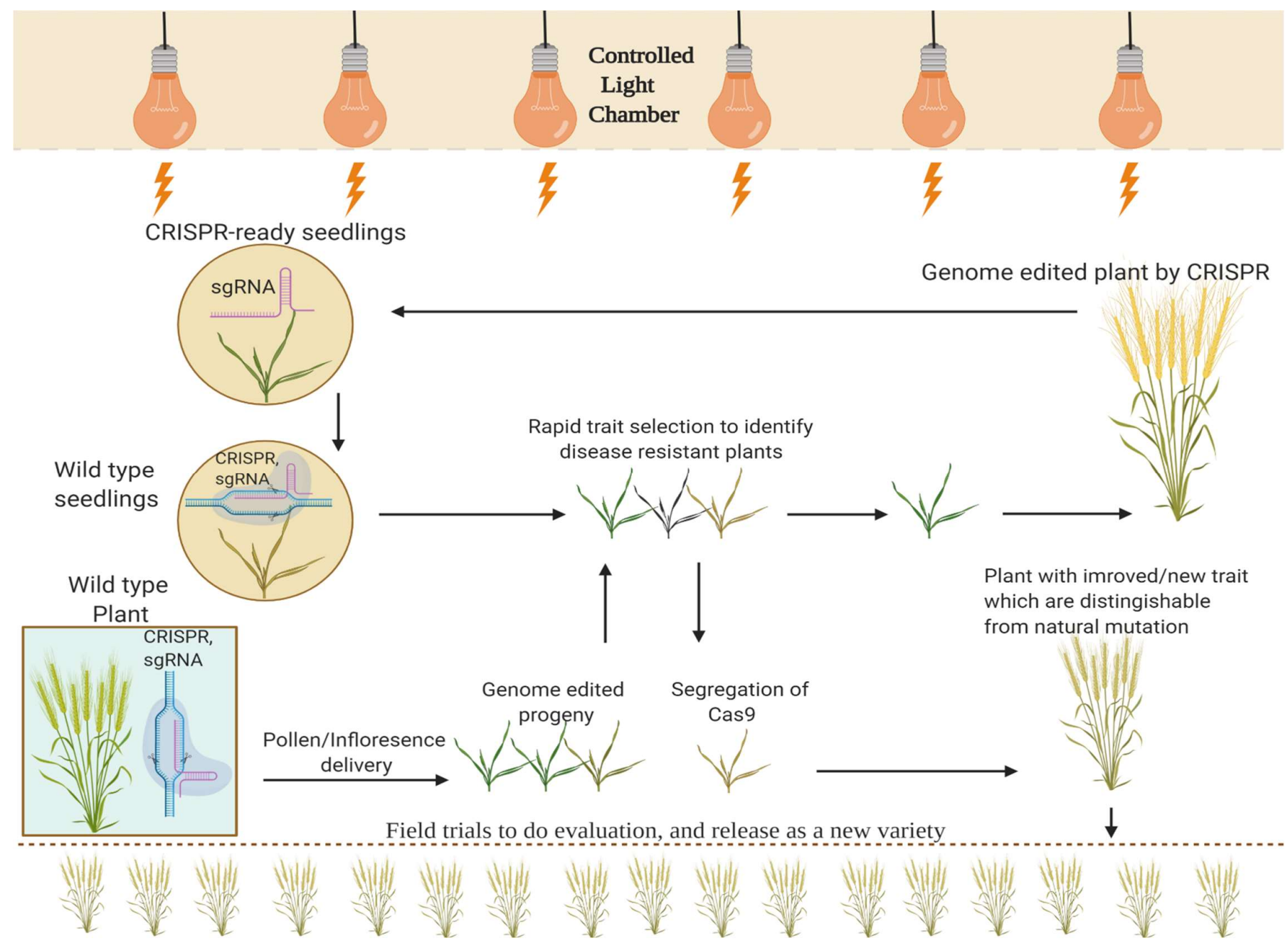

Fig 14: Speed breeding coupled with GE tools which is called as ExpressEdit approach to shorten the generation time. To save the time, Cas9 and sgRNA components of CRISPR's system, are directly applied on plants without regenerating the plants in labs. During the rapid trait selection (screening), segregated progenies are isolated, and those plants are identified which does not contains Cas9 but have new traits. While, CRISPR ready seedlings contain sgRNA, and can be used for the further gene editing of other genes.

\section{Achievements of Speed breeding:}

In wheat multiple traits related to diseases like leaf rust and root architecture that were highly variable in both the field and in greenhouses required high throughput repeatable methods for screening was easily achieved by Speed breeding. It is cost efficient and took less time in screening as compared to the conventional breeding. This robust method allows to screen the germplasm more rapidly thus proved highly efficient for variable traits ${ }^{131}$. In wheat plant height, flowering time period and resistance to several diseases can be achieved by speed breeding $^{218}$. 
In Argentina, Scarlett is most extensively cultivated cultivar of barley which is susceptible to different diseases. By taking 4 lines with modified backcrossing methodology resistant lines were developed within 2 years that were disease resistant and yields more than the cultivar ${ }^{210}$. In barley the glaucousness on the leaf sheath is an important trait for the plant to survive under hot climatic conditions ${ }^{219}$. This drought tolerant trait in Barley can be obtained by Speed breeding $^{218,220}$.

Rice is the most sensitive cereal crop to salt stress. Breeding to get salt tolerant varieties take many years which makes the task difficult. With the use of advance techniques like SNP and whole genome sequencing it becomes easier for the breeders to insert gene and then achieve several generations in each year with the help of speed breeding ${ }^{221}$. In rice a new salt tolerant line "YNU31-2-4" was developed with the help of speed breeding. After inserting genes by SNP, the breeding cycle was accelerated with the help of speed breeding methodology by using optimum light $14 \mathrm{~h}$ light and $10 \mathrm{~h}$ darkness from germination to 30 th day to allow the plant to complete its vegetative phases and after it $10 \mathrm{~h}$ light and $14 \mathrm{~h}$ darkness was provided to initiates the reproductive phase. The tillers were removed, and embryo rescue technique was used to save the time before seed maturity. Thus, enabling the researchers to get 4 to 5 generations of rice per year ${ }^{129}$.

A considerable improvement in breeding has been achieved as compared to DH technology which faces several agronomic drawbacks: low germination rate, poor vigor and sometimes distorted growth ${ }^{222}$. Moreover, developing DH lines are costlier as compared to speed breeding which don't require any specific precision ${ }^{223}$. The speed breeding with single seed descent (SSD) is useful to screen diverse germplasm within a short period of time by hastening the breeding cycles ${ }^{8}$. Single seed descent with speed breeding is time saving and cost efficient as compared to the conventional pedigree breeding method ${ }^{211}$. Moreover, speed breeding surpasses "shuttle breeding" and produces 3 times a greater number of generations. With shuttle breeding only 2 generations per year can be achieved while with speed breeding up to 6 generations can be obtained ${ }^{224}$.

\section{Conclusion:}

Two decades ago, conventional breeding was a major and easy approach toward improvement agronomic traits by exploiting the genetic variation that is caused by mutagens and cross breeding. In the present era, CRISPR/Cas9 is time efficient and a improved GE tool, as it inserts and deletes the DNA at specified genomic sites, either by NHEJ and HDR repairing 
mechanism. Despite of CRISPR/Cas9 importance, it is associated to limitations, including off target effects, and can cut only single targeted genomic site. Discovery of CRISPR/Cpf1 has played its multiplayer role by targeting the multiple genomic sites to improve the crops. Like CRISPR/Cas9, CRISPR/Cpf1 is also prone to off target effects which could lead to undesirable agronomic traits. Both GE tools require donor genomic part to put at the cleavage sites which is a complex procedure and could lead to undesirable effects in next generations.

Development of dCas9 protein has solved the problems of off target effects up to maximum extent by only requiring the gRNA to change the single nucleotide bases at targeted genomic sites. As an example, base editing, prime editing and dCas9 based epigenetic modifications works by the amalgamation of gRNA with dCas9 protein which can lead to the point mutations and increases the efficiency of GE approach. Crops which are improved by GE approaches are considered transgenic and face strict GMOs regulatory rules. These GMOs concerns are ruled out by the isolating the transgene free segregants in next generations, after the development of transgenic plants by the above stated method in "transgene free development" section.

In the present case various GE tools like SSNs (MNs, ZFNs, TALENs), CRISPR orthologs (CRISPR/Cas9 and CRISPR/Cpf1), and dCas9 based orthologs (base editing, prime editing and epigenetic genome editing) have played a tremendous role in the improvement of plant traits. The above stated methods necessitate vector construction to deliver in the vector in pursuance of its expression in plants. Speed breeding-based approach utilizes continuous lights to shorten the generation time, and it can be employed by these researchers to increase the breeding speed. Moreover, speed breeding not only develop 3-4 crops generation in a year, but also rules out the GMOs restrictions by adapting conventional breeding methods. Despite a lot of modifications in already existing molecular and conventional breeding methods, it is the dire need to further improve available breeding approaches in pursuance of ever-increasing food demand.

Funding: This research was supported by the National Key Research and Development Program of China (2016YFD0100800), the National Natural Science Foundation of China (31771798), the Fundamental Research Funds for the Central Universities (2662016PY096), and Huazhong Agricultural University Scientifc \& Technological SelfInnovation Foundation (2015RC016).We are grateful to all the partners. 


\section{References}

1. Hickey, L. T. et al. Breeding crops to feed 10 billion. Nat. Biotechnol. 37, 744-754 (2019).

2. Ahmar, S., Saeed, S., Hafeez, M., Khan, U. \& Khan, S. U. A Revolution toward GeneEditing Technology and Its Application to Crop A Revolution toward Gene-Editing Technology and Its Application to Crop Improvement. Int. J. Mol. Sci. 21, 5665 (2020).

3. Xu, J., Hua, K. \& Lang, Z. Genome editing for horticultural crop improvement. Hortic. Res. 6, 113 (2019).

4. Osakabe, Y. \& Osakabe, K. Genome editing with engineered nucleases in plants. Plant Cell Physiol. 56, 389-400 (2015).

5. Ahmar, S. et al. Conventional and molecular techniques from simple breeding to speed breeding in crop plants: Recent advances and future outlook. International Journal of Molecular Sciences 21, (2020).

6. Zhu, C. et al. Characteristics of genome editing mutations in cereal crops. Trends Plant Sci. 22, 38-52 (2017).

7. Zhang, Y., Massel, K., Godwin, I. D. \& Gao, C. Applications and potential of genome editing in crop improvement. Genome Biol. 19, 210 (2018).

8. Watson, A. et al. Speed breeding is a powerful tool to accelerate crop research and breeding. Nat. plants 4, 23-29 (2018).

9. Acquaah, G. Principles of plant genetics and breeding. (John Wiley \& Sons, 2009).

10. Holme, I. B., Gregersen, P. L. \& Brinch-Pedersen, H. Induced Genetic Variation in Crop Plants by Random or Targeted Mutagenesis: Convergence and Differences . Frontiers in Plant Science 10, 1468 (2019).

11. Breseghello, F. \& Coelho, A. S. G. Traditional and Modern Plant Breeding Methods with Examples in Rice (Oryza sativa L.). J. Agric. Food Chem. 61, 8277-8286 (2013).

12. Mba, C., Afza, R., Bado, S. \& Jain, S. M. Induced Mutagenesis in Plants Using Physical and Chemical Agents. in Plant Cell Culture: Essential Methods 111-130 (2010). doi:10.1002/9780470686522.ch7

13. Acquaah, G. Priciples of Plant Genetics Breeding. Journal of Chemical Information and Modeling 53, (2012).

14. Oladosu, Y. et al. Principle and application of plant mutagenesis in crop improvement: a review. Biotechnol. Biotechnol. Equip. 30, 1-16 (2016).

15. Khin, T. N. Rice mutation breeding for varietal improvement in Myanmar. (2006).

16. Kharkwal, M. C., Pandey, R. N. \& Pawar, S. E. Mutation Breeding for Crop Improvement. in Plant Breeding 601-645 (2004). doi:10.1007/978-94-007-1040-5_26

17. Raina, A. et al. Role of mutation breeding in crop improvement-past, present and future. Asian Res. J. Agric. 1-13 (2016).

18. Ahmed, N., Alizai, N. A., Kakar, A. H., Shah, R. \& Ali, M. MUTATION 
BREEDING: A TOOL TO IMPROVE WHEAT YIELD AND YIELD COMPONENTS. Life Sci. Int. J. 9, 3274-3279 (2015).

19. Rutger, J. N. Searching for apomixis in rice. $A R S$ (1992).

20. Kharkwal, M. C. \& Shu, Q. Y. The role of induced mutations in world food security. in Induced plant mutations in the genomics era 33-38 (2009).

21. Futsuhara, Y. Breeding of a new rice variety Reimei by gamma-ray irradiation. in Gamma Field Symp 87-109 (Nagoya Univ., Japan, 1968).

22. Awan, M. A. Use of induced mutations for crop improvement in Pakistan. in Plant mutation breeding for crop improvement. V. 1 (1991).

23. Maruyama, K., Araki, H. \& Kato, H. Thermosensitive genetic male sterility induced by irradiation. in Rice Genetics II: (In 2 Parts) 227-232 (World Scientific, 1991).

24. Gómez-Pando, L., Eguiluz, A., Jimenez, J., Falconí, J. \& Aguilar, E. H. Barley (Hordeun vulgare) and kiwicha (Amaranthus caudatus) improvement by mutation induction in Peru. in Induced Plant Mutations in the Genomics Era 371-374 (2009).

25. Rasmussen, S. K. Molecular Genetics, Genomics, and Biotechnology in Crop Plant Breeding. Agronomy 10, 439 (2020).

26. Tester, M. \& Langridge, P. Breeding technologies to increase crop production in a changing world. Science 327, 818-822 (2010).

27. Lorenz, A. J. et al. Genomic selection in plant breeding: knowledge and prospects. in Advances in agronomy 110, 77-123 (Elsevier, 2011).

28. Peleman, J. D. \& van der Voort, J. R. Breeding by design. Trends Plant Sci. 8, 330334 (2003).

29. Collard, B. C. Y. \& Mackill, D. J. Marker-assisted selection: an approach for precision plant breeding in the twenty-first century. Philos. Trans. R. Soc. London. Ser. B, Biol. Sci. 363, 557-572 (2008).

30. Pérez-de-Castro, A. M. et al. Application of genomic tools in plant breeding. Curr. Genomics 13, 179-195 (2012).

31. Varshney, R. K., Glaszmann, J.-C., Leung, H. \& Ribaut, J.-M. More genomic resources for less-studied crops. Trends Biotechnol. 28, 452-460 (2010).

32. Abdallah, N. A., Prakash, C. S. \& McHughen, A. G. Genome editing for crop improvement: Challenges and opportunities. GM Crops Food 6, 183-205 (2015).

33. Gaj, T., Gersbach, C. A. \& Barbas, C. F. 3rd. ZFN, TALEN, and CRISPR/Cas-based methods for genome engineering. Trends Biotechnol. 31, 397-405 (2013).

34. Mishra, R., Joshi, R. K. \& Zhao, K. Genome Editing in Rice: Recent Advances, Challenges, and Future Implications . Frontiers in Plant Science 9, 1361 (2018).

35. Carroll, D. Genome engineering with zinc-finger nucleases. Genetics 188, 773-782 (2011).

36. Beumer, K. J. et al. Efficient gene targeting in Drosophila by direct embryo injection with zinc-finger nucleases. Proc. Natl. Acad. Sci. 105, 19821-19826 (2008). 
37. Targeted mutagenesis using zinc-finger nucleases in ArabidopsisLloyd, A., Plaisier, C. L., Carroll, D. \& Drews, G. N. Targeted mutagenesis using zinc-finger nucleases in Arabidopsis. Proc. Natl. Acad. Sci. 102, 2232-2237 (2005).

38. Davies, J. P., Kumar, S. \& Sastry-Dent, L. Use of zinc-finger nucleases for crop improvement. in Progress in Molecular Biology and Translational Science 149, 47-63 (Elsevier, 2017).

39. Händel, E.-M., Alwin, S. \& Cathomen, T. Expanding or restricting the target site repertoire of zinc-finger nucleases: the inter-domain linker as a major determinant of target site selectivity. Mol. Ther. 17, 104-111 (2009).

40. Urnov, F. D., Rebar, E. J., Holmes, M. C., Zhang, H. S. \& Gregory, P. D. Genome editing with engineered zinc finger nucleases. Nat. Rev. Genet. 11, 636-646 (2010).

41. Kim, H. J., Lee, H. J., Kim, H., Cho, S. W. \& Kim, J.-S. Targeted genome editing in human cells with zinc finger nucleases constructed via modular assembly. Genome Res. 19, 1279-1288 (2009).

42. Petolino, J. F. Genome editing in plants via designed zinc finger nucleases. In vitro cellular \& developmental biology. Plant : journal of the Tissue Culture Association 51, 1-8 (2015).

43. Doyon, Y. et al. Heritable targeted gene disruption in zebrafish using designed zincfinger nucleases. Nat. Biotechnol. 26, 702-708 (2008).

44. Osiak, A. et al. Selection-independent generation of gene knockout mouse embryonic stem cells using zinc-finger nucleases. PLoS One 6, e28911-e28911 (2011).

45. Hauschild, J. et al. Efficient generation of a biallelic knockout in pigs using zinc-finger nucleases. Proc. Natl. Acad. Sci. 108, 12013 LP-12017 (2011).

46. Cermak, T. et al. Efficient design and assembly of custom TALEN and other TAL effector-based constructs for DNA targeting. Nucleic Acids Res. 39, e82-e82 (2011).

47. Morton, J., Davis, M. W., Jorgensen, E. M. \& Carroll, D. Induction and repair of zincfinger nuclease-targeted double-strand breaks in Caenorhabditis elegans somatic cells. Proc. Natl. Acad. Sci. 103, 16370 LP-16375 (2006).

48. Martínez-Fortún, J., Phillips, D. W. \& Jones, H. D. Potential impact of genome editing in world agriculture. Emerg. Top. Life Sci. 1, 117-133 (2017).

49. Ran, Y., Liang, Z. \& Gao, C. Current and future editing reagent delivery systems for plant genome editing. Sci. China Life Sci. 60, 490-505 (2017).

50. Cantos, C., Francisco, P., Trijatmiko, K. R., Slamet-Loedin, I. \& Chadha-Mohanty, P. $\mathrm{K}$. Identification of "safe harbor" loci in indica rice genome by harnessing the property of zinc-finger nucleases to induce DNA damage and repair. Front. Plant Sci. 5, 302 (2014).

51. Shukla, V. K. et al. Precise genome modification in the crop species Zea mays using zinc-finger nucleases. Nature 459, 437-441 (2009).

52. Chen, W. et al. Inhibiting replication of begomoviruses using artificial zinc finger nucleases that target viral-conserved nucleotide motif. Virus Genes 48, 494-501 (2014). 
53. Carlson, D. F., Fahrenkrug, S. C. \& Hackett, P. B. Targeting DNA With Fingers and TALENs. Mol. Ther. Nucleic Acids 1, e3-e3 (2012).

54. Nemudryi, A. A., Valetdinova, K. R., Medvedev, S. P. \& Zakian, S. M. TALEN and CRISPR/Cas genome editing systems: tools of discovery. Acta Naturae (англоязычная версия) 6, 19-40 (2014).

55. Boch, J. \& Bonas, U. Xanthomonas AvrBs3 family-type III effectors: discovery and function. Annu. Rev. Phytopathol. 48, 419-436 (2010).

56. Boch, J. et al. Breaking the Code of DNA Binding Specificity of TAL-Type III Effectors. Science (80-. ). 326, 1509 LP-1512 (2009).

57. Zhang, H.-X., Zhang, Y. \& Yin, H. Genome Editing with mRNA Encoding ZFN, TALEN, and Cas9. Mol. Ther. 27, 735-746 (2019).

58. Lamb, B. M., Mercer, A. C. \& Barbas, C. F. 3rd. Directed evolution of the TALE Nterminal domain for recognition of all 5' bases. Nucleic Acids Res. 41, 9779-9785 (2013).

59. Li, J.-F. et al. Multiplex and homologous recombination-mediated genome editing in Arabidopsis and Nicotiana benthamiana using guide RNA and Cas9. Nat. Biotechnol. 31, 688-691 (2013).

60. Sauer, N. J. et al. Oligonucleotide-directed mutagenesis for precision gene editing. Plant Biotechnol. J. 14, 496-502 (2016).

61. Kumar, V. \& Jain, M. The CRISPR-Cas system for plant genome editing: advances and opportunities. J. Exp. Bot. 66, 47-57 (2015).

62. Billon, P. et al. CRISPR-mediated base editing enables efficient disruption of eukaryotic genes through induction of STOP codons. Mol. Cell 67, 1068-1079 (2017).

63. Hsu, P. D. et al. DNA targeting specificity of RNA-guided Cas9 nucleases. Nat. Biotechnol. 31, 827-832 (2013).

64. Cho, S. W., Kim, S., Kim, J. M. \& Kim, J.-S. Targeted genome engineering in human cells with the Cas9 RNA-guided endonuclease. Nat. Biotechnol. 31, 230-232 (2013).

65. Hua, K., Tao, X., Yuan, F., Wang, D. \& Zhu, J.-K. Precise A· T to G· C base editing in the rice genome. Mol. Plant 11, 627-630 (2018).

66. Upadhyay, S. K., Kumar, J., Alok, A. \& Tuli, R. RNA-guided genome editing for target gene mutations in wheat. G3 (Bethesda). 3, 2233-2238 (2013).

67. Swarts, D. C. \& Jinek, M. Cas9 versus Cas12a/Cpf1: Structure-function comparisons and implications for genome editing. Wiley Interdiscip. Rev. RNA 9, e1481 (2018).

68. Rees, H. A. \& Liu, D. R. Base editing: precision chemistry on the genome and transcriptome of living cells. Nat. Rev. Genet. 19, 770-788 (2018).

69. Chen, B. et al. Expanding the CRISPR imaging toolset with Staphylococcus aureus Cas9 for simultaneous imaging of multiple genomic loci. Nucleic Acids Res. 44, e75e75 (2016).

70. Weeks, D. P., Spalding, M. H. \& Yang, B. Use of designer nucleases for targeted gene and genome editing in plants. Plant Biotechnol. J. 14, 483-495 (2016). 
71. Endo, A., Masafumi, M., Kaya, H. \& Toki, S. Efficient targeted mutagenesis of rice and tobacco genomes using Cpf1 from Francisella novicida. Sci. Rep. 6, 38169 (2016).

72. Safari, F., Zare, K., Negahdaripour, M., Barekati-Mowahed, M. \& Ghasemi, Y. CRISPR Cpfl proteins: structure, function and implications for genome editing. Cell Biosci. 9, 1-21 (2019).

73. Hsu, P. D., Lander, E. S. \& Zhang, F. Development and Applications of CRISPR-Cas9 for Genome Engineering. Cell 157, 1262-1278 (2014).

74. Jansen, R., Embden, J. D. A. van, Gaastra, W. \& Schouls, L. M. Identification of genes that are associated with DNA repeats in prokaryotes. Mol. Microbiol. 43, 1565-1575 (2002).

75. Sander, J. D. \& Joung, J. K. CRISPR-Cas systems for editing, regulating and targeting genomes. Nat. Biotechnol. 32, 347-355 (2014).

76. Haft, D. H., Selengut, J. D., Brinkac, L. M., Zafar, N. \& White, O. Genome Properties: a system for the investigation of prokaryotic genetic content for microbiology, genome annotation and comparative genomics. Bioinformatics 21, 293-306 (2005).

77. Hale, C. R. et al. RNA-guided RNA cleavage by a CRISPR RNA-Cas protein complex. Cell 139, 945-956 (2009).

78. Bolotin, A., Quinquis, B., Sorokin, A. \& Ehrlich, S. D. Clustered regularly interspaced short palindrome repeats (CRISPRs) have spacers of extrachromosomal origin. Microbiology 151, 2551-2561 (2005).

79. Wang, T., Zhang, H. \& Zhu, H. CRISPR technology is revolutionizing the improvement of tomato and other fruit crops. Hortic. Res. 6, 1-13 (2019).

80. Leong, K.-Y. B., Chan, Y.-H., Abdullah, W. M. A. N. W., Lim, S.-H. E. \& Lai, K.-S. The CRISPR/Cas9 System for Crop Improvement: Progress and Prospects. Next Gener. Plant Breed. 129 (2018).

81. Consortium, T. G. The tomato genome sequence provides insights into fleshy fruit evolution. Nature 485, 635 (2012).

82. Moon, S. Bin et al. Highly efficient genome editing by CRISPR-Cpf1 using CRISPR RNA with a uridinylate-rich 3'-overhang. Nat. Commun. 9, 1-11 (2018).

83. Liu, Y. et al. Engineering cell signaling using tunable CRISPR-Cpf1-based transcription factors. Nat. Commun. 8, 2095 (2017).

84. Zetsche, B. et al. Cpf1 is a single RNA-guided endonuclease of a class 2 CRISPR-Cas system. Cell 163, 759-771 (2015).

85. Alok, A. et al. The Rise of the CRISPR/Cpf1 System for Efficient Genome Editing in Plants. Front. Plant Sci. 11, (2020).

86. Jiang, W. et al. Demonstration of CRISPR/Cas9/sgRNA-mediated targeted gene modification in Arabidopsis, tobacco, sorghum and rice. Nucleic Acids Res. 41, e188e188 (2013).

87. Wada, N., Ueta, R., Osakabe, Y. \& Osakabe, K. Precision genome editing in plants: state-of-the-art in CRISPR/Cas9-based genome engineering. BMC Plant Biol. 20, 234 (2020). 
88. Zhang, R. et al. Generation of herbicide tolerance traits and a new selectable marker in wheat using base editing. Nat. Plants 5, 480-485 (2019).

89. Marzec, M. \& Hensel, G. Prime Editing: Game Changer for Modifying Plant Genomes. Trends Plant Sci. 25, 722-724 (2020).

90. Mishra, R., Joshi, R. K. \& Zhao, K. Base editing in crops: current advances, limitations and future implications. Plant Biotechnol. J. 18, 20-31 (2020).

91. $\mathrm{Xu}, \mathrm{R}$. et al. Development of Plant Prime-Editing Systems for Precise Genome Editing. Plant Commun. 1, 100043 (2020).

92. Adli, M. The CRISPR tool kit for genome editing and beyond. Nat. Commun. 9, 1-13 (2018).

93. Yang, L. et al. Engineering and optimising deaminase fusions for genome editing. Nat. Commun. 7, 13330 (2016).

94. Gaudelli, N. M. et al. Programmable base editing of $\mathrm{A} \bullet \mathrm{T}$ to $\mathrm{G} \bullet \mathrm{C}$ in genomic DNA without DNA cleavage. Nature 551, 464-471 (2017).

95. Xie, N., Zhou, Y., Sun, Q. \& Tang, B. Novel Epigenetic Techniques Provided by the CRISPR/Cas9 System. Stem Cells Int. 2018, 7834175 (2018).

96. Hauser, M.-T., Aufsatz, W., Jonak, C. \& Luschnig, C. Transgenerational epigenetic inheritance in plants. Biochim. Biophys. Acta (BBA)-Gene Regul. Mech. 1809, 459468 (2011).

97. Singroha, G. \& Sharma, P. Epigenetic Modifications in Plants under Abiotic Stress. in Epigenetics (IntechOpen, 2019).

98. Anzalone, A. V et al. Search-and-replace genome editing without double-strand breaks or donor DNA. Nature 576, 149-157 (2019).

99. Kosicki, M., Tomberg, K. \& Bradley, A. Repair of double-strand breaks induced by CRISPR-Cas9 leads to large deletions and complex rearrangements. Nature biotechnology 36, 765-771 (2018).

100. Haapaniemi, E., Botla, S., Persson, J., Schmierer, B. \& Taipale, J. CRISPR-Cas9 genome editing induces a p53-mediated DNA damage response. Nat. Med. 24, 927930 (2018).

101. Jaganathan, D., Ramasamy, K., Sellamuthu, G., Jayabalan, S. \& Venkataraman, G. CRISPR for Crop Improvement: An Update Review. Front. Plant Sci. 9, 985 (2018).

102. Panigrahi, R., Kariali, E., Panda, B. B., Lafarge, T. \& Mohapatra, P. K. Corrigendum to: Controlling the trade-off between spikelet number and grain filling: the hierarchy of starch synthesis in spikelets of rice panicle in relation to hormone dynamics. Funct. Plant Biol. 46, 595 (2019).

103. Witcombe, J. R., Gyawali, S., Subedi, M., Virk, D. S. \& Joshi, K. D. Plant breeding can be made more efficient by having fewer, better crosses. BMC Plant Biol. 13, 22 (2013).

104. Basnet, B. R. et al. Hybrid wheat prediction using genomic, pedigree, and environmental covariables interaction models. Plant Genome 12, 1-13 (2019). 
105. Moustafa, R. A. K. Development of Salt-tolerant High-yielding Barley Lines via Crossing Between a Mutant Induced by EMS and a Local Cultivar. in Induced plant mutations in the genomics era. Proceedings of an International Joint FAO/IAEA Symposium. Rome: Food and Agriculture Organization of the United Nations 148 À150 (2009).

106. Luzi-Kihupi, A., Shao-Mwalyego, F., Zakayo, J. A. \& Mkuya, M. Mwangaza-a new early maturing, RYMV resistant rice mutant released in the United Republic of Tanzania. Plant Mutat. Reports 2, 13-15 (2008).

107. Ahloowalia, B. S., Maluszynski, M. \& Nichterlein, K. Global impact of mutationderived varieties. Euphytica 135, 187-204 (2004).

108. Nakagawa, H. Induced mutations in plant breeding and biological researches in Japan. Crops 242, 48 (2009).

109. Patnaik, D., Chaudhary, D. \& Rao, G. J. N. Genetic improvement of long grain aromatic rices through mutation approach. (2006).

110. Rutger, J. N. Thirty years of induction, evaluation, and integration of useful mutants in rice genetics and breeding. (2006).

111. Oladosu, Y. et al. Genetic variability and selection criteria in rice mutant lines as revealed by quantitative traits. Sci. World J. 2014, (2014).

112. Rutger, J. N., Peterson, M. L. \& Hu, C. H. Registration of Calrose 76 Rice1 (Reg. No. 45). Crop Sci. 17, 978 (1977).

113. Foster, K. W. \& Rutger, J. N. Inheritance of semidwarfism in rice, Oryza sativa L. Genetics 88, 559-574 (1978).

114. Ismachin, M. A significant contribution of mutation techniques to rice breeding in Indonesia. (2006).

115. Mohamad, O. et al. Development of improved rice varieties through the use of induced mutations in Malaysia. (2006).

116. Oladosu, Y. et al. Genetic variability and diversity of mutant rice revealed by quantitative traits and molecular markers. Agrociencia 49, 249-266 (2015).

117. Rutger, J. N. \& Bryant, R. J. Registration of aromatic se rice germplasm. Crop Sci. 44, 363-a (2004).

118. Tomlekova, N. B. Induced mutagenesis for crop improvement in Bulgaria. Plant Mutat. Reports 2, 4-27 (2010).

119. Cheema, A. A. Mutation breeding for rice improvement in Pakistan: achievements and impact. (2006).

120. Balooch, A. W., Soomro, A. M., Naqvi, M. H., Bughio, H. R. \& Bughio, M. S. Sustainable enhancement of rice (Oryza sativa L.) production through the use of mutation breeding. (2006).

121. Tran, D. Q. et al. Rice mutation breeding in Institute of Agricultural Genetics, Viet Nam. (2006).

122. Do, K. T., Dao, M. S., Hung, P. Q. \& Nguyen, T. C. Rice mutation improvement for 
short duration, high yield and tolerance to adverse conditions in Mekong Delta of Viet Nam. (2006).

123. Newell-McGloughlin, M. Nutritionally improved agricultural crops. Plant Physiol. 147, 939-953 (2008).

124. Dunwell, J. M. Transgenic approaches to crop improvement. J. Exp. Bot. 51, 487-496 (2000).

125. Toojinda, T. et al. Introgression of quantitative trait loci (QTLs) determining stripe rust resistance in barley: an example of marker-assisted line development. Theor. Appl. Genet. 96, 123-131 (1998).

126. Dreher, K. et al. Is marker-assisted selection cost-effective compared to conventional plant breeding methods? The case of quality protein maize. in Proceedings of the 4th annual conference of the international consortium on agricultural biotechnology research (ICABR'00) 203-236 (2002).

127. Holme, I. B., Wendt, T. \& Holm, P. B. Intragenesis and cisgenesis as alternatives to transgenic crop development. Plant Biotechnol. J. 11, 395-407 (2013).

128. Gadaleta, A., Giancaspro, A., Blechl, A. E. \& Blanco, A. A transgenic durum wheat line that is free of marker genes and expresses 1Dy10. J. Cereal Sci. 48, 439-445 (2008).

129. Rana, M. M. et al. Salt tolerance improvement in rice through efficient SNP markerassisted selection coupled with speed-breeding. Int. J. Mol. Sci. 20, 2585 (2019).

130. Shivakumar, M. et al. Speed breeding for Indian Agriculture: a rapid method for development of new crop varieties. Curr Sci 115, 1241 (2018).

131. Alahmad, S. et al. Speed breeding for multiple quantitative traits in durum wheat. Plant Methods 14, 36 (2018).

132. Ghosh, S. et al. Speed breeding in growth chambers and glasshouses for crop breeding and model plant research. Nat. Protoc. 13, 2944-2963 (2018).

133. Riaz, A. Unlocking new sources of adult plant resistance to wheat leaf rust. (2018).

134. Shan, Q., Wang, Y., Li, J. \& Gao, C. Genome editing in rice and wheat using the CRISPR/Cas system. Nat. Protoc. 9, 2395-2410 (2014).

135. Svitashev, S. et al. Targeted mutagenesis, precise gene editing, and site-specific gene insertion in maize using Cas9 and guide RNA. Plant Physiol. 169, 931-945 (2015).

136. Xu, R. et al. Rapid improvement of grain weight via highly efficient CRISPR/Cas9mediated multiplex genome editing in rice. J. Genet. genomics $=Y i$ chuan xue bao $\mathbf{4 3}$, 529 (2016).

137. Sánchez-León, S. et al. Low-gluten, nontransgenic wheat engineered with CRISPR/Cas9. Plant Biotechnol. J. 16, 902-910 (2018).

138. Farhat, S. et al. CRISPR-Cas9 directed genome engineering for enhancing salt stress tolerance in rice. in Seminars in cell \& developmental biology 96, 91-99 (Elsevier, 2019).

139. Zhang, J., Zhang, H., Botella, J. R. \& Zhu, J. Generation of new glutinous rice by 
CRISPR/Cas9-targeted mutagenesis of the Waxy gene in elite rice varieties. J. Integr. Plant Biol. 60, 369-375 (2018).

140. Li, X. et al. High-efficiency breeding of early-maturing rice cultivars via CRISPR/Cas9-mediated genome editing. J. Genet. genomics $=$ Yi chuan xue bao 44, 175 (2017).

141. Qi, W. et al. High-efficiency CRISPR/Cas9 multiplex gene editing using the glycine tRNA-processing system-based strategy in maize. BMC Biotechnol. 16, 58 (2016).

142. Peng, A. et al. Engineering canker-resistant plants through CRISPR/Cas9-targeted editing of the susceptibility gene Cs LOB 1 promoter in citrus. Plant Biotechnol. J. 15, 1509-1519 (2017).

143. Bo, W. et al. Targeted mutagenesis of NAC transcription factor gene, OsNAC041, leading to salt sensitivity in rice. Rice Sci. 26, 98-108 (2019).

144. Zhang, M. et al. A retrotransposon in an HKT1 family sodium transporter causes variation of leaf $\mathrm{Na}+$ exclusion and salt tolerance in maize. New Phytol. 217, 11611176 (2018).

145. Miao, J. et al. Targeted mutagenesis in rice using CRISPR-Cas system. Cell Res. 23, 1233-1236 (2013).

146. Li, M. et al. Reassessment of the four yield-related genes Gn1a, DEP1, GS3, and IPA1 in rice using a CRISPR/Cas9 system. Front. Plant Sci. 7, 377 (2016).

147. Zhang, Y. et al. Analysis of the functions of Ta GW 2 homoeologs in wheat grain weight and protein content traits. Plant J. 94, 857-866 (2018).

148. Zhang, Y. et al. Efficient and transgene-free genome editing in wheat through transient expression of CRISPR/Cas9 DNA or RNA. Nat. Commun. 7, 1-8 (2016).

149. Liang, Z. et al. Efficient DNA-free genome editing of bread wheat using CRISPR/Cas9 ribonucleoprotein complexes. Nat. Commun. 8, 1-5 (2017).

150. Smulders, M. J. M., Jouanin, A. A. \& Gilissen, L. J. W. J. Gene editing using CRISPR/Cas9 to modify or remove gliadins from wheat and produce coeliac disease epitope-free wheat. in Proceedings of the 31st Meeting of the Working Group on Prolamin Analysis and Toxicity 63-68 (2018).

151. Bhowmik, P. et al. Targeted mutagenesis in wheat microspores using CRISPR/Cas9. Sci. Rep. 8, 1-10 (2018).

152. Dayani, S., Sabzalian, M. R. \& Mazaheri-Tirani, M. CRISPR/Cas9 Genome Editing in Bread Wheat (Triticum aestivum L.) Genetic Improvement. in Advances in Plant Breeding Strategies: Cereals 453-469 (Springer, 2019).

153. Liang, Z. et al. Genome editing of bread wheat using biolistic delivery of CRISPR/Cas9 in vitro transcripts or ribonucleoproteins. Nat. Protoc. 13, 413 (2018).

154. Wang, W. et al. Transgenerational CRISPR-Cas9 activity facilitates multiplex gene editing in allopolyploid wheat. Cris. J. 1, 65-74 (2018).

155. Singh, M., Kumar, M., Albertsen, M. C., Young, J. K. \& Cigan, A. M. Concurrent modifications in the three homeologs of Ms45 gene with CRISPR-Cas9 lead to rapid generation of male sterile bread wheat (Triticum aestivum L.). Plant Mol. Biol. 97, 
371-383 (2018).

156. Zhou, J. et al. Gene targeting by the TAL effector PthXo2 reveals cryptic resistance gene for bacterial blight of rice. Plant J. 82, 632-643 (2015).

157. Sun, Y. et al. Generation of high-amylose rice through CRISPR/Cas9-mediated targeted mutagenesis of starch branching enzymes. Front. Plant Sci. 8, 298 (2017).

158. Zhang, Y. et al. Simultaneous modification of three homoeologs of Ta EDR 1 by genome editing enhances powdery mildew resistance in wheat. Plant J. 91, 714-724 (2017).

159. Wang, F. et al. Enhanced rice blast resistance by CRISPR/Cas9-targeted mutagenesis of the ERF transcription factor gene OsERF922. PLoS One 11, e0154027 (2016).

160. Li, J. et al. Generation of thermosensitive male-sterile maize by targeted knockout of the ZmTMS5 gene. J. Genet. genomics= Yi chuan xue bao 44, 465 (2017).

161. Yao, L. et al. OsMATL mutation induces haploid seed formation in indica rice. Nat. Plants 4, 530-533 (2018).

162. Zeng, Y., Wen, J., Zhao, W., Wang, Q. \& Huang, W. Rational Improvement of Rice Yield and Cold Tolerance by Editing the Three Genes OsPIN5b, GS3, and OsMYB30 With the CRISPR-Cas9 System. Front. Plant Sci. 10, 1663 (2020).

163. Li, J. et al. Gene replacements and insertions in rice by intron targeting using CRISPR-Cas9. Nat. plants 2, 1-6 (2016).

164. Sun, Y. et al. Engineering herbicide-resistant rice plants through CRISPR/Cas9mediated homologous recombination of acetolactate synthase. Mol. Plant 9, 628-631 (2016).

165. Butt, H. et al. Efficient CRISPR/Cas9-mediated genome editing using a chimeric single-guide RNA molecule. Front. Plant Sci. 8, 1441 (2017).

166. Shi, J. et al. ARGOS8 variants generated by CRISPR-Cas9 improve maize grain yield under field drought stress conditions. Plant Biotechnol. J. 15, 207-216 (2017).

167. Wang, Y. et al. Simultaneous editing of three homoeoalleles in hexaploid bread wheat confers heritable resistance to powdery mildew. Nat. Biotechnol. 32, 947-951 (2014).

168. Shi, J. et al. The maize low-phytic acid mutant lpa2 is caused by mutation in an inositol phosphate kinase gene. Plant Physiol. 131, 507-515 (2003).

169. Yin, X., Anand, A., Quick, P. \& Bandyopadhyay, A. Editing a stomatal developmental gene in rice with CRISPR/Cpf1. in Plant Genome Editing with CRISPR Systems 257268 (Springer, 2019).

170. Malzahn, A. A. et al. Application of CRISPR-Cas12a temperature sensitivity for improved genome editing in rice, maize, and Arabidopsis. BMC Biol. 17, 1-14 (2019).

171. Li, S. et al. Expanding the scope of CRISPR/Cpf1-mediated genome editing in rice. Mol. Plant 11, 995-998 (2018).

172. Xu, R. et al. Generation of targeted mutant rice using a CRISPR-Cpf1 system. Plant Biotechnol. J. 15, 713-717 (2017).

173. Wang, M., Mao, Y., Lu, Y., Tao, X. \& Zhu, J. Multiplex gene editing in rice using the 
CRISPR-Cpf1 system. Mol. Plant 10, 1011-1013 (2017).

174. Lee, K. et al. Activities and specificities of CRISPR/Cas9 and Cas12a nucleases for targeted mutagenesis in maize. Plant Biotechnol. J. 17, 362-372 (2019).

175. $\mathrm{Xu}, \mathrm{R}$. et al. Enhanced genome editing in rice using single transcript unit CRISPRLbCpf1 systems. Plant Biotechnol. J. 17, 553 (2019).

176. Tang, X. et al. A CRISPR-Cpf1 system for efficient genome editing and transcriptional repression in plants. Nat. plants 3, 1-5 (2017).

177. Zhong, Z. et al. Plant genome editing using FnCpf1 and LbCpf1 nucleases at redefined and altered PAM sites. Mol. Plant 11, 999-1002 (2018).

178. Li, T., Liu, B., Spalding, M. H., Weeks, D. P. \& Yang, B. High-efficiency TALENbased gene editing produces disease-resistant rice. Nat. Biotechnol. 30, 390-392 (2012).

179. Char, S. N. et al. Heritable site-specific mutagenesis using TALENs in maize. Plant Biotechnol. J. 13, 1002-1010 (2015).

180. Shan, Q., Zhang, Y., Chen, K., Zhang, K. \& Gao, C. Creation of fragrant rice by targeted knockout of the OsBADH2 gene using TALEN technology. Plant Biotechnol. J. 13, 791-800 (2015).

181. Shan, Q. et al. Rapid and efficient gene modification in rice and Brachypodium using TALENs. Mol. Plant 6, 1365-1368 (2013).

182. Kelliher, T. et al. MATRILINEAL, a sperm-specific phospholipase, triggers maize haploid induction. Nature 542, 105-109 (2017).

183. Liang, Z., Zhang, K., Chen, K. \& Gao, C. Targeted mutagenesis in Zea mays using TALENs and the CRISPR/Cas system. J. Genet. Genomics 41, 63-68 (2014).

184. Schornack, S., Meyer, A., Römer, P., Jordan, T. \& Lahaye, T. Gene-for-gene-mediated recognition of nuclear-targeted AvrBs3-like bacterial effector proteins. J. Plant Physiol. 163, 256-272 (2006).

185. Ainley, W. M. et al. Trait stacking via targeted genome editing. Plant Biotechnol. J. 11, 1126-1134 (2013).

186. Gao, H. et al. Heritable targeted mutagenesis in maize using a designed endonuclease. Plant J. 61, 176-187 (2010).

187. Djukanovic, V. et al. Male-sterile maize plants produced by targeted mutagenesis of the cytochrome $\mathrm{P} 450$-like gene (MS 26) using a re-designed I-C reI homing endonuclease. Plant J. 76, 888-899 (2013).

188. Youssef, D. et al. Induction of targeted deletions in transgenic bread wheat (Triticum aestivum L.) using customized meganuclease. Plant Mol. Biol. Report. 36, 71-81 (2018).

189. Lu, Y. \& Zhu, J.-K. Precise Editing of a Target Base in the Rice Genome Using a Modified CRISPR/Cas9 System. Molecular plant 10, 523-525 (2017).

190. Hu, B. et al. Variation in NRT1.1B contributes to nitrate-use divergence between rice subspecies. Nat. Genet. 47, 834-838 (2015). 
191. Ikeda, A. et al. slender Rice, a Constitutive Gibberellin Response Mutant, Is Caused by a Null Mutation of the SLR1 Gene, an Ortholog of the Height-Regulating Gene GAI/RGA/RHT/D8. Plant Cell 13, 999 LP-1010 (2001).

192. Li, J., Sun, Y., Du, J., Zhao, Y. \& Xia, L. Generation of targeted point mutations in rice by a modified CRISPR/Cas9 system. Mol. Plant 10, 526-529 (2017).

193. Zong, Y. et al. Precise base editing in rice, wheat and maize with a Cas9-cytidine deaminase fusion. Nat. Biotechnol. 35, 438 (2017).

194. Gallego-Bartolomé, J. et al. Targeted DNA demethylation of the Arabidopsis genome using the human TET1 catalytic domain. Proc. Natl. Acad. Sci. 115, E2125-E2134 (2018).

195. Stuitje, A. R. et al. Seed-expressed fluorescent proteins as versatile tools for easy (co) transformation and high-throughput functional genomics in Arabidopsis. Plant Biotechnol. J. 1, 301-309 (2003).

196. Durr, J., Papareddy, R., Nakajima, K. \& Gutierrez-Marcos, J. Highly efficient heritable targeted deletions of gene clusters and non-coding regulatory regions in Arabidopsis using CRISPR/Cas9. Sci. Rep. 8, 4443 (2018).

197. Yu, H. \& Zhao, Y. Fluorescence marker-assisted isolation of Cas9-free and CRISPRedited Arabidopsis plants. in Plant Genome Editing with CRISPR Systems 147-154 (Springer, 2019).

198. Gao, X., Chen, J., Dai, X., Zhang, D. \& Zhao, Y. An effective strategy for reliably isolating heritable and Cas9-free Arabidopsis mutants generated by CRISPR/Cas9mediated genome editing. Plant Physiol. 171, 1794-1800 (2016).

199. Lu, H. et al. CRISPR-S: an active interference element for a rapid and inexpensive selection of genome-edited, transgene-free rice plants. Plant Biotechnol. J. 15, 1371 (2017).

200. Hu, J. et al. The rice pentatricopeptide repeat protein RF5 restores fertility in HongLian cytoplasmic male-sterile lines via a complex with the glycine-rich protein GRP162. Plant Cell 24, 109-122 (2012).

201. Wang, Z. et al. Cytoplasmic male sterility of rice with boro II cytoplasm is caused by a cytotoxic peptide and is restored by two related PPR motif genes via distinct modes of mRNA silencing. Plant Cell 18, 676-687 (2006).

202. He, Y. et al. Programmed self-elimination of the CRISPR/Cas9 construct greatly accelerates the isolation of edited and transgene-free rice plants. Mol. Plant 11, 1210 1213 (2018).

203. Andersson, M. et al. Efficient targeted multiallelic mutagenesis in tetraploid potato (Solanum tuberosum) by transient CRISPR-Cas9 expression in protoplasts. Plant Cell Rep. 36, 117-128 (2017).

204. Lin, C. et al. Application of protoplast technology to CRISPR/Cas9 mutagenesis: from single-cell mutation detection to mutant plant regeneration. Plant Biotechnol. J. 16, 1295-1310 (2018).

205. Wang, S. et al. Efficient targeted mutagenesis in potato by the CRISPR/Cas9 system. Plant Cell Rep. 34, 1473-1476 (2015). 
206. Subburaj, S. et al. Site-directed mutagenesis in Petunia $\times$ hybrida protoplast system using direct delivery of purified recombinant Cas9 ribonucleoproteins. Plant Cell Rep. 35, 1535-1544 (2016).

207. Malnoy, M. et al. DNA-free genetically edited grapevine and apple protoplast using CRISPR/Cas9 ribonucleoproteins. Front. Plant Sci. 7, 1904 (2016).

208. Murovec, J., Guček, K., Bohanec, B., Avbelj, M. \& Jerala, R. DNA-free genome editing of Brassica oleracea and B. rapa protoplasts using CRISPR-Cas9 ribonucleoprotein complexes. Front. Plant Sci. 9, 1594 (2018).

209. Chiurugwi, T., Kemp, S., Powell, W. \& Hickey, L. T. Speed breeding orphan crops. Theor. Appl. Genet. 132, 607-616 (2019).

210. Hickey, L. T. et al. Speed breeding for multiple disease resistance in barley. Euphytica 213, 64 (2017).

211. O'Connor, D. J. et al. Development and application of speed breeding technologies in a commercial peanut breeding program. Peanut Sci. 40, 107-114 (2013).

212. Fiyaz, R. A. et al. Speed Breeding: Methods and Applications. in Accelerated Plant Breeding, Volume 1 31-49 (Springer, 2020).

213. Lowe, K. et al. Morphogenic Regulators Baby boom and Wuschel Improve Monocot Transformation. Plant Cell 28, 1998 LP-2015 (2016).

214. Richardson, T., Thistleton, J., Higgins, T. J., Howitt, C. \& Ayliffe, M. Efficient Agrobacterium transformation of elite wheat germplasm without selection. Plant Cell, Tissue Organ Cult. 119, 647-659 (2014).

215. Doudna, J. A. \& Charpentier, E. The new frontier of genome engineering with CRISPR-Cas9. Science (80-. ). 346, (2014).

216. Hamada, H. et al. An in planta biolistic method for stable wheat transformation. Sci. Rep. 7, 1-8 (2017).

217. Wang, M. et al. Gene Targeting by Homology-Directed Repair in Rice Using a Geminivirus-Based CRISPR/Cas9 System. Molecular plant 10, 1007-1010 (2017).

218. Ghosh, S. et al. Speed breeding in growth chambers and glasshouses for crop breeding and model plant research. Nat. Protoc. 13, 2944-2963 (2018).

219. Hen-Avivi, S. et al. A metabolic gene cluster in the wheat $\mathrm{W} 1$ and the barley Cer-cqu loci determines $\beta$-diketone biosynthesis and glaucousness. Plant Cell 28, 1440-1460 (2016).

220. Zhang, Z. et al. W3 is a new wax locus that is essential for biosynthesis of $\beta$-diketone, development of glaucousness, and reduction of cuticle permeability in common wheat. PLoS One 10, e0140524 (2015).

221. Munns, R. \& Tester, M. Mechanisms of salinity tolerance. Annu. Rev. Plant Biol. 59, 651-681 (2008).

222. Fund, S. A. D., Ferrie, A. \& Waterer, D. Development of Improved Spice Crops using Double Haploid Technology. (Citeseer, 2009).

223. Chaikam, V., Molenaar, W., Melchinger, A. E. \& Boddupalli, P. M. Doubled haploid 
technology for line development in maize: technical advances and prospects. Theor. Appl. Genet. 1-17 (2019).

224. Ortiz, R. et al. High yield potential, shuttle breeding, genetic diversity, and a new international wheat improvement strategy. Euphytica 157, 365-384 (2007). 